\title{
Brassinosteroids make plant life easier under abiotic stresses mainly by modulating major components of antioxidant defense system
}

\author{
Bojjam V. Vardhini ${ }^{1 *}$ and Naser A. Anjum ${ }^{2}$ \\ 'Department of Botany, Telangana University, Nizamabad, India \\ ${ }^{2}$ CESAM-Centre for Environmental and Marine Studies and Department of Chemistry, University of Aveiro, Aveiro, Portugal
}

\section{Edited by:}

Rene Kizek, Central European Institute of Technology, Czech Republic

\section{Reviewed by:}

Harminder Pal Singh, Panjab

University, India

Yogesh Abrol, Bhagalpur University, India

*Correspondence:

Bojjam V. Vardhini, Department of Botany, Telangana University,

Dichpally, Nizamabad 503322, India e-mail: drvidyavardhini@

rediffmail.com
Various abiotic stress factors significantly contribute to major worldwide-losses in crop productivity by mainly impacting plant's stress tolerance/adaptive capacity. The latter is largely governed by the efficiency of antioxidant defense system for the metabolism of elevated reactive oxygen species (ROS), caused by different abiotic stresses. Plant antioxidant defense system includes both enzymatic (such as superoxide dismutase, SOD, E.C. 1.15.1.1; catalase, CAT, E.C. 1.11.1.6; glutathione reductase, GR, E.C. 1.6.4.2; peroxidase, POD, E.C. 1.11.1.7; ascorbate peroxidase, APX, E.C. 1.11.1.11; guaiacol peroxidase, GPX, E.C. 1.11.1.7) and non-enzymatic (such as ascorbic acid, AsA; glutathione, $\mathrm{GSH}$; tocopherols; phenolics, proline etc.) components. Research reports on the status of various abiotic stresses and their impact on plant growth, development and productivity are extensive. However, least information is available on sustainable strategies for the mitigation of abiotic stress-mediated major consequences in plants. Brassinosteroids (BRs) are a novel group of phytohormones with significant growth promoting nature. BRs are considered as growth regulators with pleiotropic effects, as they influence diverse physiological processes like growth, germination of seeds, rhizogenesis, senescence etc. and also confer abiotic stress resistance in plants. In the light of recent reports this paper: (a) overviews major abiotic stresses and plant antioxidant defense system, (b) introduces BRs and highlights their significance in general plant growth and development, and (c) appraises recent literature available on BRs mediated modulation of various components of antioxidant defense system in plants under major abiotic stresses including metals/metalloids, drought, salinity, and temperature regimes. The outcome can be significant in devising future research in the current direction.

Keywords: abiotic stress, reactive oxygen species, antioxidant defense system, tolerance, brassinosteroids

\section{INTRODUCTION}

\section{ABIOTIC STRESSES AND PLANT ANTIOXIDANT DEFENSE SYSTEM}

Plants are inevitably exposed to various environmental stress factors of like abiotic and biotic types. In particular, abiotic stresses such as temperature (heat, chilling, and freezing), water (drought, water logging), salt, heavy metals, light (intense and weak), radiation $(\mathrm{UV}-\mathrm{A} / \mathrm{B})$ etc. are serious threats to agriculture worldwide (Bray et al., 2000). Elevation in the generation of various reactive oxygen species (ROS; such as superoxide radicals, $\mathrm{O}^{2-}$; hydroxyl radicals, $\mathrm{OH}^{-}$; perhydroxyl radicals, $\mathrm{HO}^{2-}$; alkoxy radicals, $\mathrm{RO}^{-}$; hydrogen peroxide, $\mathrm{H}_{2} \mathrm{O}_{2}$; singlet oxygen, ${ }_{1} \mathrm{O}^{2}$.) is a common consequence in plants growing under abiotic stresses (Anjum et al., 2010, 2012, 2014; Gill and Tuteja, 2010). Important signal transduction functions and triggering and/or orchestration of plant responses to varied (abiotic) stresses can be possible with minimal levels of ROS. However, major ROS and their reaction products that escape antioxidant-mediated scavenging can disturb the ROS/antioxidant homeostasis in plant cells, cause oxidative stress, bring critical damages to the primary metabolites of plants viz., proteins, lipids, carbohydrates and DNA and halt cellular metabolism (Anjum et al., 2010, 2012, 2014; Gill and Tuteja, 2010). To survive such stresses, plants have evolved many intricate defense mechanisms to increase their tolerance and survive under such extreme environmental conditions. Plant stress tolerance requires the activation of complex metabolic activities including antioxidative pathways, especially ROS-scavenging systems within the cells that in turn can contribute to continued plant growth under stress conditions (El-Mashad and Mohamed, 2012). Plant antioxidant defense system consists of the enzymes such as superoxide dismutase (SOD: EC 1.15.1.1), catalase (CAT: EC 1.11.1.6), peroxidase (POD: EC 1.11.1.11), ascorbate peroxidase (APX: E.C. 1.11.1.11), glutathione reductase (GR: EC 1.6.4.2), glutathione sulfo-transferase (GST: EC), polyphenol oxidase (PPO: E.C. 1.14.18.1), guaiacol peroxidase (GPX: EC 1.11.1.7), monodehydroascorbate reductase (MDHAR: EC 1.1.5.4), dehydroascorbate reductase (DHAR: EC 1.8.5.1) etc. Whereas, non-enzymatic components may include osmolytes like proline, glycine betaine, sorbital, mannitol etc., and reduced glutathione (GSH), ascorbic 
acid (AsA) that are needed for osmotic adjustment, stabilization of membranes, and ROS-scavenging (Anjum et al., 2010, 2012, 2014; Gill and Tuteja, 2010) (Figure 1).

\section{BRASSINOSTEROIDS OVERVIEW}

Brassinosteroids (BRs) are a new type of polyhydroxy steroidal phytohormones with significant growth-promoting influence (Vardhini, 2012a,b; Bajguz and Piotrowska-Niczyporuk, 2014). Mitchell et al. (1970) discovered BRs which were later extracted from the pollen of Brassica napus by Grove et al. (1979). BRs can be classified as $\mathrm{C}_{27}, \mathrm{C}_{28}$ or $\mathrm{C}_{29}$ BRs according to the number of carbons in their structure (Vardhini, 2013a,b). Sixty BRs related

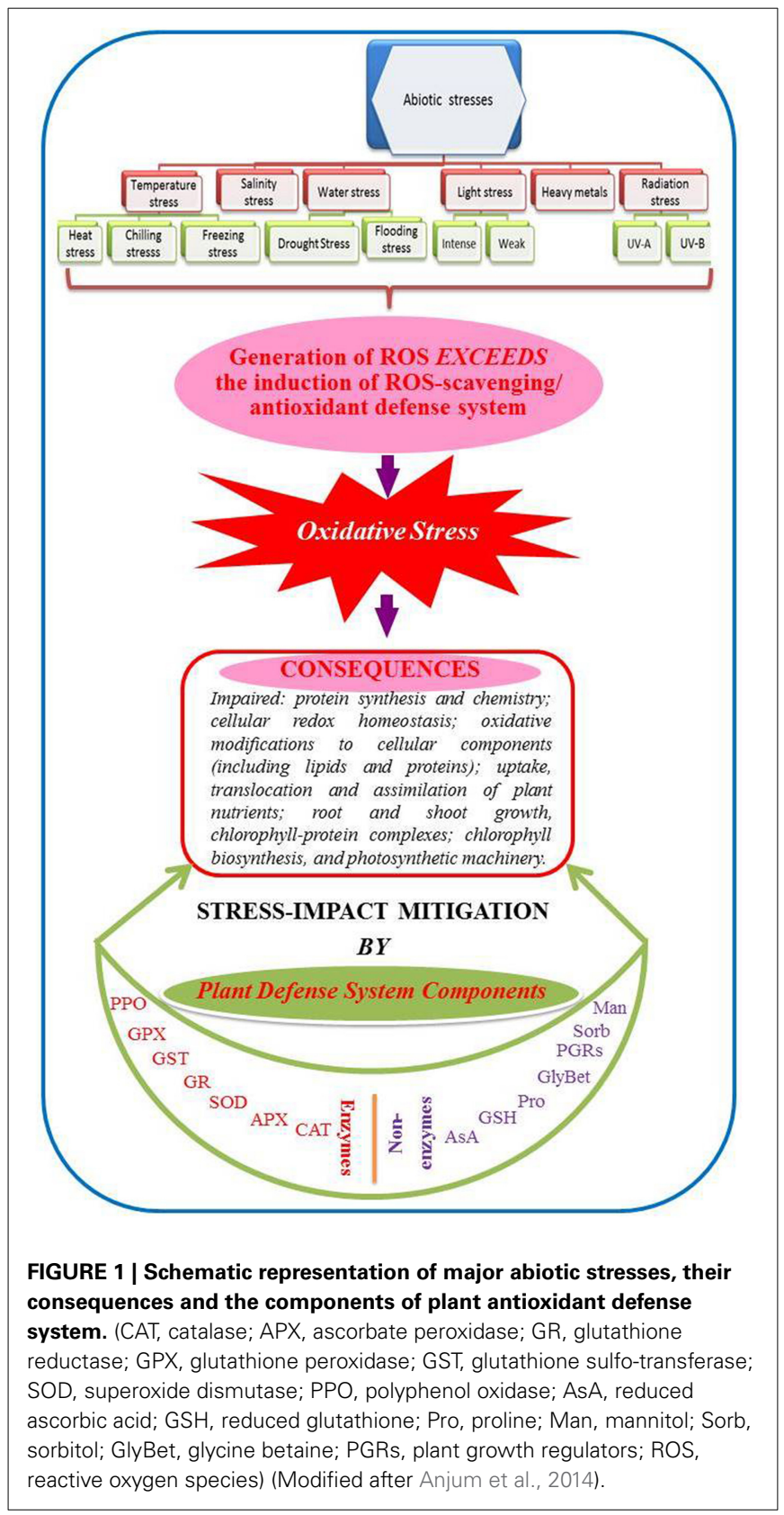

compounds have also been identified (Haubrick and Assmann, 2006). However, brassinolide (BL), 28-homobrassinolide (28HomoBL) and 24-epibrassinolide (24-EpiBL) are the three bioactive BRs those are widely used in most physiological and experimental studies (Vardhini et al., 2006) (Figure 2). BRs are considered ubiquitous in plant kingdom as they are found in almost all the phyla of the plant kingdom like alga, pteridophyte, gymnosperms, dicots and monocots (Bajguz, 2009). BRs are considered also as a new group of plant growth hormones that perform a variety of physiological roles like growth, seed germination, rhizogenesis, senescence, and resistance to plants against various abiotic stresses (Rao et al., 2002).

\section{SIGNIFICANCE IN GENERAL PLANT GROWTH AND DEVELOPMENT}

BRs have to their credit a host of roles in general plant growth and development. BRs can activate the cell cycle during seed germination (Zadvornova et al., 2005), control progression of cell cycle (González-Garcia et al., 2011), induce exaggerated growth in hydroponically grown plants (Arteca and Arteca, 2001), and also control proliferation of leaf cells (Nakaya et al., 2002). In addition, reports are also available on the role of BRs in growth promotion of apical meristems in potato tubers (Meudt et al., 1983), acceleration of rate of cell division in isolated protoplasts of Petunia hybrida (Ho, 2003) and cell division and leaf expansion (Zhiponova et al., 2013). Initially BRs were identified based on their growth promoting activities; however, subsequent physiological and genetic studies revealed additional functions of BRs in regulating a wide range of processes, including source/sink

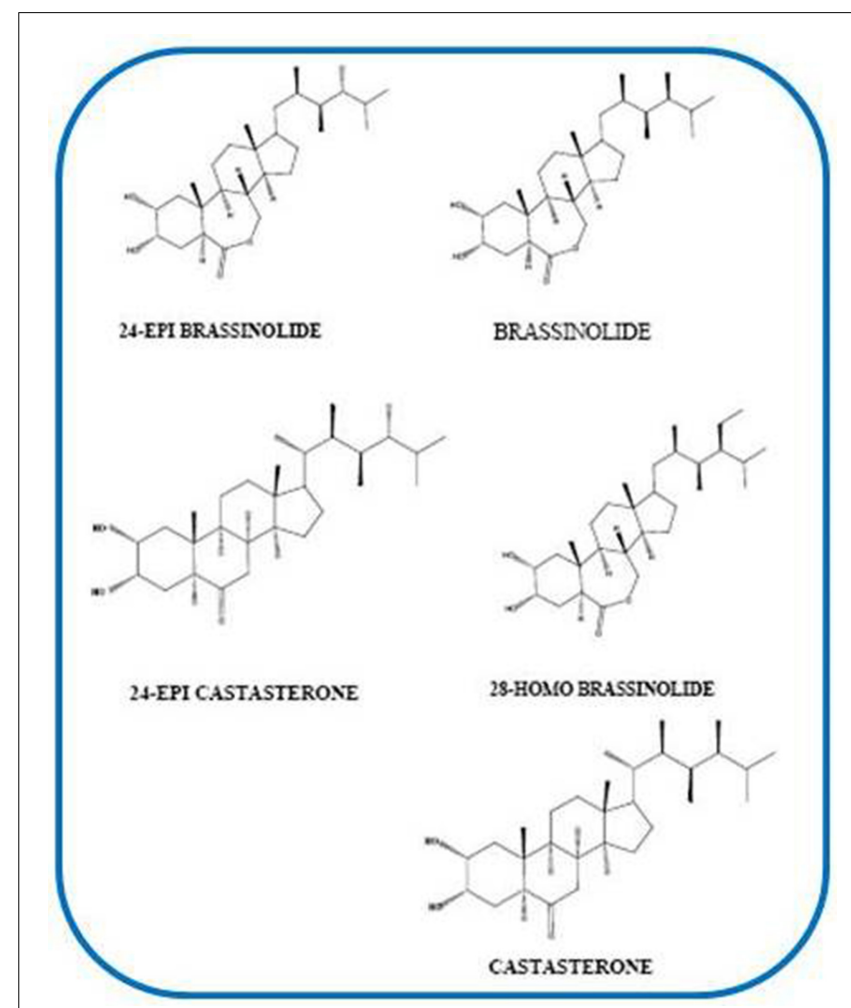

FIGURE 2 | Examples of commonly used bioactive brassinosteroids. 
relationships, seed germination, photosynthesis, senescence, photomorphogenesis, flowering and responses to different abiotic and biotic stresses (Deng et al., 2007). The work with BR biosynthetic mutants in Arabidopsis thaliana (Tao et al., 2004) and Pisum sativum (Nomura et al., 1997) have provided strong evidences that BRs are essential for plant growth and development and BR- signaling plays a positive in plant growth and development (Fábregas and Caño-Delgado, 2014). A simple BR- analog $2 \alpha$, 3 $\alpha$-dihydroxy-17 $\beta$-(3-methyl butynyloxyl) 7-oxa-B-homo-5 $\alpha$ androstan-6-one induces bean second node splitting which is considered as the prominent physiological feature of BRs (Strnad and Kohout, 2003). Dwarf and de-etiolated phenotypes and BRdeficient species of some Arabidopsis mutants were rescued by application of BRs (Bishop and Yakota, 2001). Even Pharbitis nil, Uzukobito was a defective BR- biosynthetic dwarf mutant strain (Suzuki et al., 2003) which emphasized that BR-deficient and defective BR-biosynthetic species exhibited abnormal growth. Friedrichsen et al. (2002) also reported that three redundant BR genes encode transcription factors which are required for normal growth, indicating the necessity of BRs for normal growth. Similarly, the inhibition of growth (Asami et al., 2000) and secondary xylem development (Nagata et al., 2001) of cress (Lepidius sativus) by brassinozole, a specific inhibitor of BL synthesis was reversed by the exogenous application of $\mathrm{BL}$, further emphasizing the necessity of BRs for normal plant growth.

BRs also exhibit synergistic effect with other phyohormones in regulating the plant growth and metabolism. BRs interact with auxins, cytokinins, gibberellins (Domagalska et al., 2010), abscisic acid (ABA) (Domagalska et al., 2010), ethylene (ET) (Manzano et al., 2011) salicylic acid (SA) (Divi et al., 2010) and jasmonic acid (JA) (Creelman and Mullet, 1997; Peng et al., 2011) to promote plant growth and metabolism. Ability of 24-EpiBL to control the basic thermotolerance and salt tolerance of the mutants has been evidenced (Divi et al., 2010). In addition, these authors also reported synergistic role of 24-EpiBL, where treatment with 24-EpiBL increased expression of various hormone marker genes in both wild type and mutant Arabidopsis seedlings those were either deficient in or insensitive to ABA, ET, JA, and SA. Notably, BRs may be applied/supplied to plants at different stages of their life cycle viz., vegetative stage (Vardhini and Rao, 1998), flowering stage (Vardhini, 2012a, 2013a), meiosis stage (Saka et al., 2003), grain filling stage (Vardhini, 2012a), anthesis stage (Liu et al., 2006) etc. as foliar spray (Vardhini et al., 2008), seed treatment (Zhang et al., 2007; Kartal et al., 2009), root application (Shang et al., 2006; Song et al., 2006) and even as shot gun approach (Hayat et al., 2010a). Examples of a range of other major functions of BRs and related compounds reported in different plants can be found in Figure 3.

\section{BRASSINOSTEROIDS-MEDIATED MODULATION OF PLANT ANTIOXIDANT DEFENSE SYSTEM UNDER MAJOR ABIOTIC STRESS}

Extensive research over the years' has established stress-impactmitigating role of BRs and associated compounds in different plants exposed to various abiotic stresses such as high temperature (Zhou et al., 2004; Kurepin et al., 2008; Janeczko et al., 2011), low temperature in terms of chilling (Divi and Krishna,
2010; Liu et al., 2011; Wang et al., 2014) as well as freezing (Janeczko et al., 2009). Reports are available on the significance of BRs and associated compounds in different plants exposed to salinity (Avalbaev et al., 2010; Abbas et al., 2013), light (Wang et al., 2010, 2012; Kurepin et al., 2012; Li et al., 2012a), drought (Anjum et al., 2011; Li et al., 2012b; Mahesh et al., 2013), flooding (Lu et al., 2006; Liang and Liang, 2009), metals/metalloids (Arora et al., 2010a,b; Ashraf et al., 2010; Bajguz, 2010), herbicides (Sharma et al., 2013a), pesticides (Xia et al., 2006), insecticides (Xia et al., 2009b, 2011), organic pollutants (Ahammed et al., 2012a, 2013a), newly reclaimed sandy soil (Ahmed and Shalaby, 2013) and preservatives (Hu et al., 2014).

Hereunder, recent reports on the role of BRs (and associated compounds) in the modulation of both enzymatic and non-enzymatic components of antioxidant defense system in abiotic stressed plants are critically appraised. The discussion will consider primarily metals/metalloids followed by temperature regimes (high and low), drought, salinity and other major abiotic stresses.

\section{METAL/METALLOID STRESS}

Foliar application of homoBL was reported to improve Cdtolerance in Brassica juncea through increasing activity of antioxidative enzymes (such as CAT, POD, SOD) and the content of osmolyte (such as proline) (Hayat et al., 2007). Improved Cdtolerance in Phaseolus vulgaris was possible as a result of 24-epiBL $(5 \mu \mathrm{M})$-mediated increased activity of antioxidative enzymes, and proline content and subsequent improvements in the membrane stability index (MSI), relative leaf water content (RLWC) (Rady, 2011). Nullification of the damaging effect of Cd was reported in totamato cultivars (K-25 and Sarvodya) as a result of 28homoBL/24-epiBL $\left(10\left(^{-8}\right) \mathrm{M}\right)$-mediated improvement in photosynthetic machinery and antioxidant defense system (Hasan et al., 2011). Application of BRs $\left(10^{-8} \mathrm{M}\right)$ to $\mathrm{Cd}$ (3.0, 6.0, 9.0, and $12 \mathrm{mg} \mathrm{kg}^{-1}$ ) stressed Solanum lycopersicum plants enhanced antioxidant system activity and improved fruit yield and quality (Hayat et al., 2012). Cd-impact-ameliorative role of 24-epiBL and 28-homoBL $(3.0 \mu \mathrm{M})$ was evidenced in Raphanus sativus, where these BRs enhanced levels of free proline, antioxidant enzymes CAT, SOD, APX, GPX, and also reduced the activity of POD and AAO (Anuradha and Rao, 2007b). In Cd (0.5, 1.0, and $1.5 \mathrm{mM}$ )-exposed Raphanus sativus, a diminished oxidative stress via 24 -epiBL $\left(10^{-7}, 10^{-9}\right.$, and $\left.10^{-11} \mathrm{M}\right)$-supplementationmediated elevation in the activity of GST and PPO enzymes was reported (Sharma et al., 2012). Earlier, these authors evidenced 28-homoBL $\left(10^{-11}, 10^{-9}\right.$, and $\left.10^{-7} \mathrm{M}\right)$-assisted amelioration of Cd $(0.5,1.0$, and $1.5 \mathrm{mM})$ impacts in Raphanus sativus, where improved biomass and seedling growth was argued as a result of 28-homoBL-mediated regulation of the activity of APX, CAT, GR, POD, and SOD (Sharma et al., 2010). Hasan et al. (2008) also reported 28- homoBL-mediated elevated activity of CAT, POD, and SOD and the protection of Cicer arietinum against Cd (50, 100 , or $150 \mu \mathrm{M})$.

Application of 24-epiBL ameliorated Ni-stress in Brassica juncea by enhancing mainly the activity of antioxidant enzymes (Kanwar et al., 2013). Earlier, these authors reported BRs (24EpiBL, CS, dolicholide and typhasterole)-mediated significant 


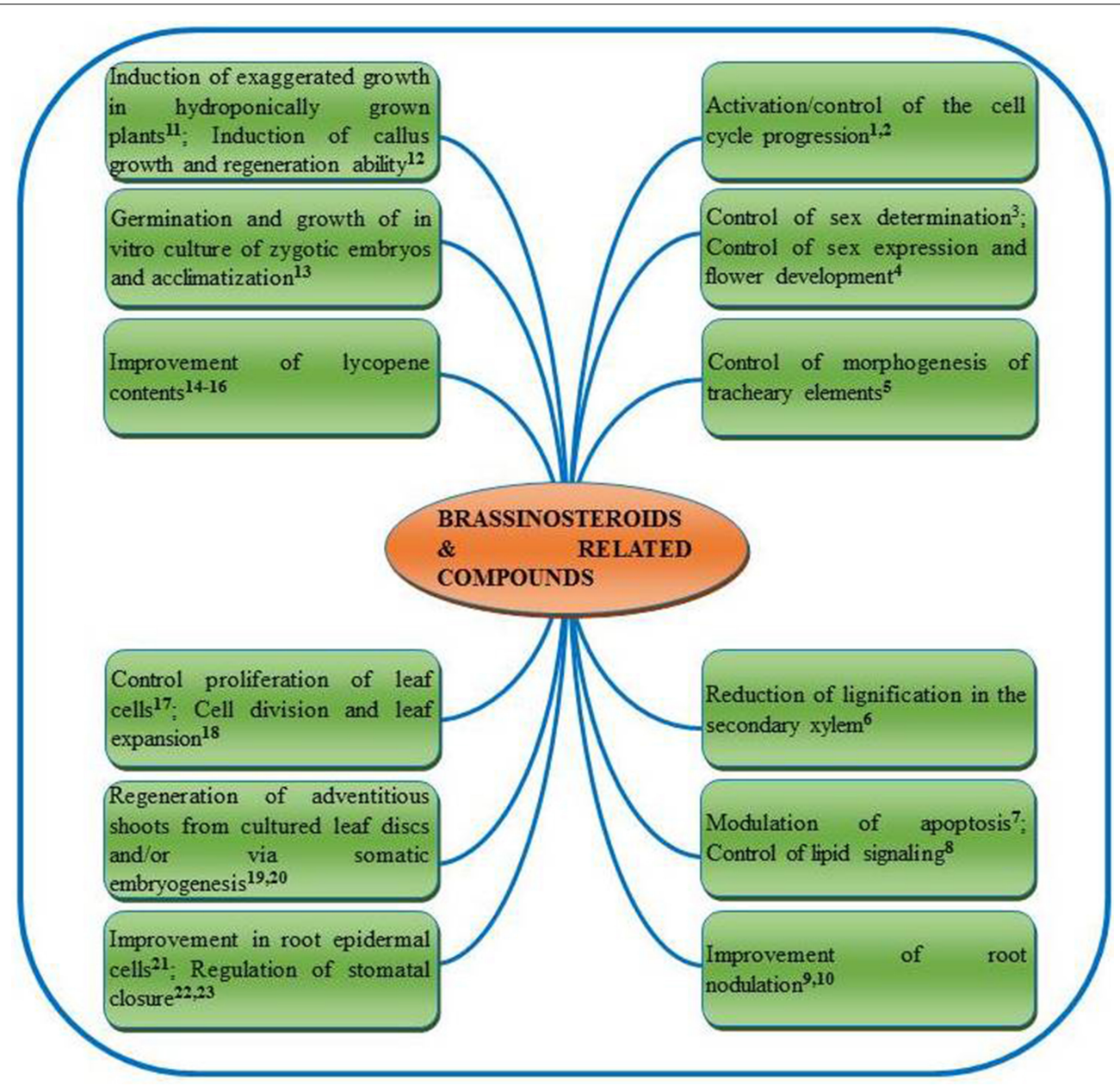

FIGURE 3 | Summarized roles of brassinosteroids and related compounds reported in plants. 'Zadvornova et al., 2005; ${ }^{2}$ González-Garcia et al., 2011; ${ }^{3}$ Hartwig et al., 2011; ${ }^{4}$ Manzano et al., 2011; ${ }^{5}$ Yamamoto et al., 2001; ${ }^{6}$ Jin et al., 2014; ${ }^{7}$ Carange et al., 2011; ${ }^{8}$ Pokotylo et al., 2014; ${ }^{9}$ Vardhini and Rao, 1999; ${ }^{10}$ Upreti and Murti,
2004; ${ }^{11}$ Arteca and Arteca, 2001; ${ }^{12}$ Lu et al., 2003; ${ }^{13}$ Borcioni and Bonato-Negrelle, 2012; ${ }^{14}$ Vardhini and Rao, 2002; ${ }^{15}$ Weng et al., 2007; ${ }^{16}$ Vogler et al., 2014; ${ }^{17}$ Nakaya et al., 2002; ${ }^{18}$ Zhiponova et al., 2013; ${ }^{19}$ Malabadi and Nataraja, 2007; ${ }^{20}$ Aydin et al., $2006 ;{ }^{21}$ Cheng et al., 2014; ${ }^{22}$ Haubrick et al., 2006; ${ }^{23}$ Xia et al., 2014. mitigation of $\mathrm{Ni}(0.2,0.4$, and $0.6 \mathrm{mM})$-stress in Brassica juncea plants by elevating the activity of ROS-metabolizing enzymes (and also via lowering the metal uptake) (Kanwar et al., 2012). Significantly elevated activity of antioxidant enzymes (such as GPX, CAT, GR, APX, and SOD) in Brassica juncea seedlings emerged from the homoBL $(0.01,1.0$, and $100 \mathrm{nM})$-treated seeds was argued to provide tolerance of this plant to $\mathrm{Ni}$ concentrations $\left(25,50\right.$, and $100 \mathrm{mg} \mathrm{dm}^{-3}$ ) (Sharma et al., 2008). In Brassica juncea, the spraying of homoBL was evidenced to partially neutralize the toxic effect of 50 or $100 \mu \mathrm{M} \mathrm{Ni}$, where elevated activity of POD and CAT, and content of proline was observed in leaves and roots (Alam et al., 2007). Spraying of 24-epiBL $(1.0 \mu \mathrm{M})$ to Ni-exposed Brassica juncea was reported to detoxify Ni-impacts (Ali et al., 2008a). Elevated CAT, POD, and SOD activity via the spray of $0.01 \mu \mathrm{M}$ of 28 -homoBL was argued to protect five wheat (Triticum aestivum) cultivars (PBW-373, UP-2338, DL-LOK-01, DL-373, and HD-2338) against Ni concentrations (50 and $100 \mu \mathrm{M}$ ) (Yusuf et al., 2011b). Raphanus sativus seedlings emerged from seeds pre-soaked in 24-epiBL, exhibited elevated activity of APX, SOD, CAT, GPX, MDHAR, DHAR, and GR; that eventually resulted in reducing lipid peroxidation, enhanced proline and protein contents, and improved enhancing the root/shoot length, fresh biomass under Ni exposure (Sharma et al., 2011a). Application of $10^{-6}$ M 24-epiBL as shotgun approach (pre-sowing seed soaking) to the Ni-stressed T-44 (Ni-tolerant) and PDM-139 (Ni-sensitive) varieties of Vigna radiata plants improved biological yield, number of nodules, leghemoglobin content, and the activity of CAT, POD, and SOD enzymes. The 24-epiBL-mediated up-regulation of antioxidant enzyme activity and the elevated level of proline (osmolyte) were argued to confer Ni-tolerance and improve growth, nodulation and yield attributes (Yusuf et al., 2012). Recently, these authors reported BRs-mediated improved antioxidant defense (and also nitrogen metabolism) in two contrasting cultivars of Vigna radiata under different levels of Ni (Yusuf et al., 2014).

The role of BRs and associated compounds in the mitigation of elevated levels of $\mathrm{Cu}$ has also been reported in plants. To this end, treatment of Brassica juncea seedlings with $10^{-10}, 10^{-8}$, and 
$10^{-6} \mathrm{M}$ homoBL improved growth and photosynthetic traits via decreased $\mathrm{H}_{2} \mathrm{O}_{2}$ and elevated activity of CAT, POD, and SOD (Fariduddin et al., 2009b). Recently, these authors reported an improved growth of $\mathrm{NaCl}+\mathrm{Cu}\left(100 \mathrm{mg} \mathrm{kg}^{-1}\right)$ stressed Cucumis sativus via epiBL-mediated enhancements in the activity of CAT, POD, and SOD (Fariduddin et al., 2013a). Supplemantation of $10^{-7}, 10^{-9}$, and $10^{-11} \mathrm{M} 24$-epiBL to Raphanus sativus ameliorated the oxidative stress caused by $\mathrm{Hg}(0.5,1.0$, and $1.5 \mathrm{mM})$ by enhancing the activity of ROS-metabolizing enzymes such as GST and PPO (Sharma et al., 2012). Recently, 24-epiBL $\left(10^{-7}, 10^{-9}, 10^{-11} \mathrm{M}\right)$-mediated increased activity of antioxidative enzymes such as SOD, CAT, APOX, GPX, GR, MDHAR and DHAR, and also the contents of GSH were argued to help radish plants to counteract the consequences of $\mathrm{Hg}$ (Kapoor et al., 2014).

Supplementation of 24-epiBL reduced $\mathrm{Pb}$ toxicity and enhanced the growth in radish (Raphanus sativus L.) seedlings by increasing the activities of antioxidant enzymes like CAT, APX, GPX, SOD and reducing POD activity (Anuradha and Rao, 2007a). Mitigation of the consequences of $\mathrm{Pb}(100$ or $200 \mu \mathrm{M})$ was reported in tomato plants as a result of 24-epiBL-mediated increases in the activities of SOD, CAT, APX and GR, and the contents of AsA and GSH (Rady and Osman, 2012). 24-epiBL ameliorated $\mathrm{Cr}$ (VI) stress in 7-d old Raphanus sativus L. cv. "Pusa chetki" seedlings by enhancing the pools of reduced GSH and AsA, the activity of GR, SOD, and APX enzymes, and also the contents of phytochelatins, proline, and glycinebetaine (Choudhary et al., 2011). Co-application of epiBL and spermidine (polyamine) was also evidenced to remarkably enhance the titers of antioxidants (GSH, AsA, proline, glycine betaine and total phenols) and the activity of GPX, SOD, and GR) in Cr-stressed Raphanus sativus (Choudhary et al., 2011). Seed pre-soaking treatment of 28 -homoBL at $10^{(-7)} \mathrm{M}$ was effective in ameliorating $\mathrm{Cr}(\mathrm{VI})$ stress in Raphanus sativus L. (Pusa Chetaki), where an increased activity of antioxidative enzymes (except GPX) and the contents of proline and proteins but reduced lipid peroxidation were evidenced (Sharma et al., 2011b). 24-EpiBL-mediated diminution of Cr-toxicity in Brassica juncea was reported, where increased activity of GPX, CAT, GR, APX, SOD, MDHAR, and DHAR was argued to improve plant health (Arora et al., 2010b). Amelioration of Al-impacts was evidenced through epiBL or homoBL spraying to mung bean (Vigna radiata), where these BRs increased RLWC, water use efficiency, photosynthetic rate via enhancing the activity of antioxidative enzymes such as CAT, POD, and SOD in leaves (Ali et al., 2008b). Plant tolerance to Pb (and also to $\mathrm{Cu}$ and $\mathrm{Cr}$ ) is possible via BL-mediated significant activation of enzymes (such as SOD, CAT, APX, and GR) and non-enzymes (such as reduced GSH, total AsA) (Bajguz, 2010) (Table 1).

Least reports are available on the role of BRs in plants under $\mathrm{Zn}, \mathrm{Bo}, \mathrm{Co}, \mathrm{Mn}$, and As stress. Supplementation of 28-homoBL to Raphanus sativus seedlings was reported to help this plant to tolerate $\mathrm{Zn}$ toxicity by enhancing antioxidative enzyme activities, strengthening GSH metabolism and redox status, and improving the contents of non-enzymatic antioxidants and proteins (Ramakrishna and Rao, 2013). The role of 28-homoBL (Arora et al., 2008b) and that of 24-epiBL (Arora et al., 2010a) was reported respectively in Zea mays and Brassica juncea under Zn stress. In the previous studies, increased activity of SOD, CAT, APOX, GPX, GR, MDHAR and DHAR and the contents of GSH were reported to control $\mathrm{Zn}$-accrued lipid peroxidation. Application of 28 -homoBL $\left(10^{(-8)} \mathrm{M}\right)$ to Bo $(0.50,1.0$, and $2.0 \mathrm{mM}$ )-exposed Vigna radiata improved the growth, water relations, photosynthesis by enhancing antioxidant enzymes (such as CAT, POD and SOD) (Yusuf et al., 2011a). Foliar spray treatment with 24-epiBL $\left(0,10^{-10}, 10^{-8}\right.$, and $\left.10^{-6} \mathrm{M}\right)$ alleviated the stress generated by Co $\left(0,5 \times 10^{-4}, 10^{-3}, 1.5 \times 10^{-3}\right.$, and $2 \times 10^{-3}$ $\mathrm{M})$ ion in Brassica juncea through significantly improving the activities of SOD, CAT, POD, GR, APOX, MDHAR, and DHAR enzymes (Arora et al., 2012). Under elevated lelevs of Mn, epiBL application was reported to enhance the activities of SOD, POD, CAT, APX, DHAR, and GR, and the contents of AsA, and GSH that eventually controlled lipid peroxidation and metabolized superoxide radical and $\mathrm{H}_{2} \mathrm{O}_{2}$ in Zea mays (Wang et al., 2009). Recently, Raghu et al. (2014) reported BRs-mediated improved As-tolerance in Raphanus sativus as a result of increased activity of SOD and CAT.

\section{TEMPERATURE REGIMES}

BRs and associated compounds have been extensively reported to modulate different components of antioxidant defense system and to play a positive role in the mitigation of the consequences in different plants exposed to both high (Mazorra et al., 2002, 2011; Zhou et al., 2004; Cao and Zhao, 2007; Ogweno et al., 2008; Hayat et al., 2010b) and low (Janeczko et al., 2007; Liu et al., 2009; Kumar et al., 2010; Aghdam et al., 2012; Wang et al., 2012; Hu et al., 2013; Xi et al., 2013; Aghdam and Mohammadkhani, 2014) temperatures (Table 1).

Young seedlings of two Indica rice (Oryza sativa) cultivars namely Xieqingzao B (heat-sensitive) and 082 (heat-tolerant), subjected to high temperature; sprayed with $0.005 \mathrm{mg} \mathrm{L}^{-1}$ of BR exhibited significant enhancement in activities of POD and SOD isozyme expression levels, reduction in MDA level and leakage of leaf electrolytes (Cao and Zhao, 2007). Supplementation with 28 -homoBL to Vigna radiata c.v. T-44 plants detoxified the stress generated by high temperature by improving the membrane stability index (MSI), leaf water potential $(\psi)$ via increased the activities of antioxidative enzymes and the level of proline (Hayat et al., 2010b). Pre-treatment of 24-epiBL to Lycopersicon esculentum Mill. cv. 9021 plants exposed to high temperature $\left(40 / 30^{\circ} \mathrm{C}\right.$; for 8 days) significantly alleviated high-temperaturecaused inhibition of photosynthesis by increasing the activities of SOD, APX, GPX, and CAT, and reducing total $\mathrm{H}_{2} \mathrm{O}_{2}$ and MDA contents (Ogweno et al., 2008). Pre-incubation of tomato leaf discs with 24-epiBL or $\mathrm{MH}_{5}$ (polyhydroxylated spirostanic analog of BR) (for $24 \mathrm{~h}$ ) stimulated the activities of CAT, POD and SOD, controlled cell damage under heat stress $\left(40^{\circ} \mathrm{C}\right)$ (Mazorra et al., 2002). EpiBL-induced tolerance to heat shock (HS) in tomato seedlings (BR-deficient mutant, extreme dwarf $d(x)$ ), a partially BR-insensitive mutant $\mathrm{Curl}_{3}$ (-abs) allele ( $\mathrm{curl}_{3}$ altered brassinolide sensitivity; and a line overexpressing the dwarf, BR-biosynthesis gene, 35SD) was argued as a result of reduced ion leakage, lipid peroxidation through enhanced activities of antioxidative enzymes (Mazorra et al., 2011). 
Table 1 | Summary of representative studies on brassinosteroids (BRs) and related compounds in the mitigation of major abiotic stress-impacts in different plant species.

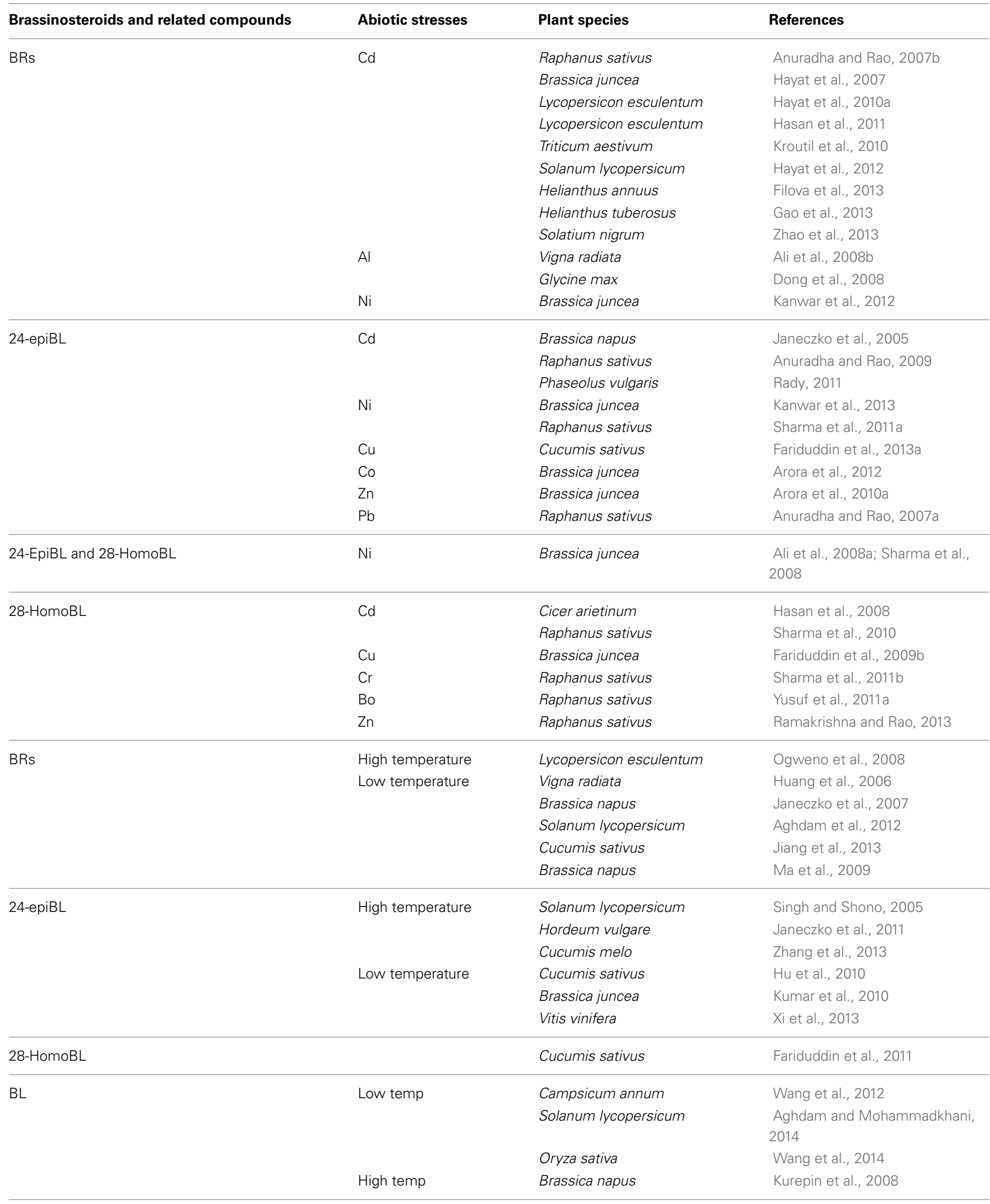


Table 1 | Continued

\section{Brassinosteroids and related compounds}

BRs
Abiotic stresses

Drought

Flooding

Drought

$B L$

Flooding

24-EpiBL

Drought

\section{Plant species}

Phaseolus vulgaris

Sorghum vulgare

Lycopersicon esculentum

Solanum lycopersicum

Carica papaya

Raphanus sativus

Brassica napus

\section{References}

Upreti and Murti, 2004

Vardhini and Rao, 2005

Behnamnia et al., 2009

Yuan et al., 2010

Gomes et al., 2013

Mahesh et al., 2013

Liang and Liang, 2009

Li et al., 2008

Zhang et al., 2008

Li and Feng, 2011

Savaliya et al., 2013

Arachis hypogaea

Cucumis sativus

Glycine max

Lu et al., 2006

Hu et al., 2013

Mousavi et al., 2009

Kang et al., 2009

Fariduddin et al., 2009a

Ali et al., 2006

Shang et al., 2006

Song et al., 2006

Shahbaz and Ashraf, 2007

Wang et al., 2011

Daur and Tatar, 2013

Sharma et al., 2013b

Trifolium alexandrinum

Oryza sativa

Medicago sativa

Zea mays

Vigna unguiculata

Oryza sativa

Cucumis sativus

Triticum aestivum

Pisum sativum

Cucumis sativus

Cajanus cajan

Capsicum annuum

Lactuca sativa

Solanum melongena

Phaseolus vulgaris

Pisum sativum

Cajanus cajan

Fragaria $x$ ananassa

Triticum aestivum

Hordeum vulgare

Triticum aestivum

Cicer arietinum

Zea mays

Vigna radiata

Triticum aestivum

Brassica juncea
Zhang et al., 2007

El-Khallal et al., 2009

El-Mashad and Mohamed, 2012

Das et al., 2013

Lu and Yang, 2013

Talaat and Shawky, 2013

Fedina, 2013

Fariduddin et al., 2013a

Dalio et al., 2013

Abbas et al., 2013

Ekinci et al., 2012

Rady, 2011

Shahid et al., 2011

Durigan et al., 2011

Karlidag et al., 2011

Avalbaev et al., 2010

Tabur and Demir, 2009

Shahbaz et al., 2008

Ali et al., 2007

Arora et al., 2008a

Hayat et al., 2010b

Yusuf et al., 2011b

Alyemeni et al., 2013
Ding et al., 2012 
Literature is full also on the role of BRs in plants under low temperature stress. BR infiltration prior to cold treatment can reduce the ion leakage in chilling-exposed rape plants (Janeczko et al., 2007); whereas, 24-epiBL can increase the antioxidant defense (and also osmoregulation) in chilling stressed young grapevines (Xi et al., 2013). Application of 24EpiBL to suspension cultured cells of low temperature (4 and $0^{\circ} \mathrm{C}$ )-exposed Chorispora bungeana alleviated oxidative damage through enhancing the activity of ROS-metabolizing enzymes such as APX, CAT, POD and SOD and the content of AsA (Liu et al., 2009). In chilling ( $4^{\circ} \mathrm{C}$ ) exposed Brassica juncea seedlings, exogeniously applied 24-epiBL alleviated the toxic effect of $\mathrm{H}_{2} \mathrm{O}_{2}$ through increasing the activities of various enzymes involved in antioxidant defense system like CAT, APX, and SOD (Kumar et al., 2010). Hu et al. (2010) reported that exogenous application of 24 -epiBL alleviated the $12 / 8^{\circ} \mathrm{C}$ chilling-induced inhibition of photosynthesis in cucumber (Cucumis sativus) by reducing ROS generation and accumulation through increasing the activities of SOD, APX. In another study on cucumber pretreated with 24-epiBL ( 0.3 and $1.0 \mathrm{mmol} \cdot \mathrm{L}^{-1}$ chlorpyrifos) and exposed to chilling stress, these authors reported elevations in the activities of APX, GR, CAT, and GPX that eventually alleviated the chillingaccrued phytotoxicity (Hu et al., 2013). 28-homoBL $\left(10^{-8}\right.$, or $10^{-6} \mathrm{M}$ )-mediated significantly increased activities of antioxidant enzymes like CAT, POD, and SOD (and also the elevated content of proline) in cucumber (Cucumis sativus) were reported to improve tolerance of this plant to chilling temperatures $\left(10 / 8^{\circ} \mathrm{C}\right.$, $5 / 3^{\circ} \mathrm{C}$ ) (Fariduddin et al., 2011; BRs 5, 10, and $15 \mu \mathrm{M}$ ) effectively reduced chilling injury of pepper fruit during 18-day storage at $3^{\circ} \mathrm{C}$ by reducing the electrolyte leakage, MDA content; increasing the activities of antioxidant enzymes including CAT, POD, APX, and GR (Wang et al., 2012). Aghdam et al. (2012) reported that treatments with 3.0 and $6.0 \mu \mathrm{M}$ BRs to tomato fruits stored at $1^{\circ} \mathrm{C}$ for 21 days reduced the chilling injury, electrolyte leakage, MDA content; enhanced proline, total phenol contents, phenylalanine ammonia-lyase (PAL) activity and maintained membrane integrity. In a recent work, these authors reported that application of 0,3 and $6 \mu \mathrm{M} \mathrm{BL}$ to tomato fruits subjected to $1^{\circ} \mathrm{C}$ chilling stress can inhibit the activities of phospholipase D (PLD) and lipoxygenase (LOX), major causes of chilling injury induction in tomato fruits (Aghdam and Mohammadkhani, 2014). BRs protected the photosynthetic apparatus from cold-induced damage in Cucumis sativus plants by activating the enzymes of Calvin cycle and increasing the antioxidant capacity, which in turn mitigated the photo-oxidative stress and plant growth inhibition during the recovery of chilling injury (Jiang et al., 2013).

\section{DROUGHT STRESS}

Reports are extensive on the role of BRs and related compounds in plant drought tolerance (Li and Van Staden, 1998a,b; Li et al., 1998, 2008, 2012b; El-Khallal, 2002; Vardhini and Rao, 2003a,b, 2005; Zhang et al., 2008; Behnamnia et al., 2009; Fariduddin et al., 2009a; Farooq et al., 2010; Yuan et al., 2010; Anjum et al., 2011; Mahesh et al., 2013). Field and pot experiments of $0.2 \mathrm{mg} \mathrm{L}^{-1} \mathrm{BL}$ application to 1-year-old Robinia pseudoacacia seedlings grown under drought stress increased the activity of SOD, POD and CAT, and the contents of soluble sugars and free proline (Li et al.,
2008). Application of $0.1 \mu \mathrm{M} 24$-epiBL increased the resistance in drought-stressed Chorispora bungeana by reducing the lipid peroxidation (measured in terms of MDA content), membrane permeability as a result of increased activities of antioxidative enzymes and the pools of non-enzymatic antioxidants such as AsA and GSH (Li et al., 2012b). BL ameliortaed the negative effect water stress (Poly Ethylene Glycol:PEG for $24 \mathrm{~h}$ ) on callus tissues of drought-resistant (PAN 6043) and drought-sensitive (SC 701) cultivars of Zea mays by enhancing the activities of SOD, CAT, APX, POD, and GR (Li and Van Staden, 1998a,b). Earlier also, BL was reported to increase the activities of SOD, CAT, and APX eznymes, and the contents of AsA and total carotenoids in seedlings of drought-resistant (PAN 6043) and drought-sensitive (SC 701) cultivars of Zea mays under water stress (-1.0 MPa PEG 6000) (Li et al., 1998). Exogenous application of $\mathrm{BL}$ alleviated the detrimental effects of drought in Zea mays by enhancing enzymatic antioxidant enzyme activities and the contents of proteins, relative leaf water and proline (Anjum et al., 2011). 28-HomoBL and 24-epiBL ameliorated the negative impact of PEG-imposed osmotic/water stress in CSH-14, ICSV (Vardhini and Rao, 2003a) and CSH-15 (Vardhini and Rao, 2005) varieties of Sorghum vulgare seedlings by increasing the activity of CAT and the contents of free proline and nucleic acids. Seedlings of Triticum cultivars Sakha 69 (drought-resistant) and Giza 164 (drought-sensitive) subjected to water stress (by soaking the roots for $48 \mathrm{~h}$ in $30 \%$ PEG $6000 ;-0.9 \mathrm{MPa}$ ) and BR treatment, exhibited higher RWLC, MSI, proline, regulation of expression of water stress-inducible proteins as well as induced de-novo synthesis of specific polypeptides (El-Khallal, 2002). Exogenously applied 24epiBL $(0.01 \mu \mathrm{M})$ improved the drought tolerance in rice (Oryza sativa) cultivar Super-Basmati which was sturdily associated with the greater tissue water potential, increased synthesis of metabolites and enhanced capacity of antioxidant system (Farooq et al., 2010). Spraying with HBL $(0.01 \mu \mathrm{M})$ to 30 -day stage seedlings of Brassica juncea subjected to drought stress (for 7 days at the 8-14 $\left(D_{1}\right) / 15-21\left(D_{2}\right)$ days stage of growth) improved the activities of antioxidant enzymes such as CAT, POD and SOD, and the content of proline (Fariduddin et al., 2009a). Foliar application of BRs elevated the activities of POD and SOD, increased the concentrations of soluble sugars and proline that eventualy resulted into decreased MDA concentration and electrical conductivity in the leaves of drought exposed Glycine max (Zhang et al., 2008). Lycopersicon esculentum, subjected to drought stress and pretreated with BR showed increased activities of POD, SOD, CAT and APX, and the contents of non-enzymatic antioxidants such as AsA and proline (Behnamnia et al., 2009). Yuan et al. (2010) also reported that $1.0 \mu \mathrm{M} 24$-epiBL treatment significantly alleviated water stress and increased the activities of antioxidant enzymes such as CAT, APX, and SOD that decresaed the levels of $\mathrm{H}_{2} \mathrm{O}_{2}$ and MDA in two Lycopersicon esculentum genotypes viz., Mill. cv. Ailsa Craig (AC) and its ABA-deficient mutant notabilis (not). 24-epiBL and 28-homoBL-mediated reduction in the inhibitory effect of water stress on seed germination and seedling growth of radish (Raphanus sativus) subjected to water stress (imposed by $15 \%(\mathrm{w} / \mathrm{v})$ PEG) was a result of elevated levels of SOD, CAT and APX and the free proline content (Mahesh et al., 2013) (Table 1). 


\section{SALINITY STRESS}

Modulation of various components of antioxidant defense system via BRs and associated compounds in salinity exposed plants has been extensively reported (Nunez et al., 2003; Özdemir et al., 2004; Song et al., 2006; Shahbaz and Ashraf, 2007; Zhang et al., 2007; Ali et al., 2008b; Arora et al., 2008a; El-Khallal et al., 2009; Hayat et al., 2010b; Rady, 2011; Vardhini, 2011; Ding et al., 2012; El-Mashad and Mohamed, 2012; Abbas et al., 2013; Fariduddin et al., 2013b; Lu and Yang, 2013; Sharma et al., 2013b) (Table 1). BL mitigated the negative impact of salt stress in Zea mays by inducing the activities of different antioxidant enzymes (El-Khallal et al., 2009). Application of 28-homoBL $\left(10^{-7}, 10^{-9}\right.$, and $\left.10^{-11} \mathrm{M}\right)$ for 7 days improved seedling growth, lipid peroxidation via elevating antioxidative enzyme activities (SOD, CAT, GR, APX, and GPX) in the seedlings of Zea mays (var. Partap-1) subjected to salt $(25,50,75$, and $100 \mathrm{mM} \mathrm{NaCl}$ ) stress (Arora et al., 2008a). 24-EpiBL applied as a foliar spray could alleviate the adverse effects of salt on two hexaploid wheat (Triticum aestivum) cultivars, S-24 (salt tolerant) and MH-97 (moderately salt sensitive), grown in saline conditions $(150 \mathrm{mM}$ of $\mathrm{NaCl}$ ) by enhancing the activity of POD and CAT (Shahbaz and Ashraf, 2007). BL treatment increased the activities of CAT, SOD and GR; reduced the activities of POD and PPO of two varieties of sorghum plants ("CSH-5" and "CSH-6") grown in two saline experimental sites of Karaikal (Varchikudy and Mallavur), thus indicating its ability to counteract the negative impact of saline stress (Vardhini, 2011). Exogenous BL (0.01 mg $\times$ L $(-1)$ markedly decreased the salt stress index, mortality rate, MDA, electrolyte leakage via enhancing the activities of SOD, POD, and CAT in Cucumis sativus seedlings (Song et al., 2006). Exogenous BR $\left(0.005,0.01,0.05,0.1\right.$, and $\left.0.2 \mathrm{mg} / \mathrm{L}^{-1}\right)$ protected Cucumis sativus seedlings against salt stress by elevating the activity of SOD, POD and CAT, and that in turn distinctly lowered the salt injured index $(40.2 \%)$ and increased the contents of free-proline, soluble sugars (Shang et al., 2006). Application of epiBL to salinity-exposed Cucumis sativus seedlings decreased leaf superoxide anion production rate, $\mathrm{H}_{2} \mathrm{O}_{2}, \mathrm{MDA}$, cell membrane permeability, improved seedlings growth as a result of increased the activities of SOD, POD, CAT (Lu and Yang, 2013). Application of epiBL to the $\mathrm{Cu}+\mathrm{NaCl}(150 \mathrm{mM})$ stressed seeds of two cultivars (Rocket and Jumbo) of Cucumis sativus plant enhanced the activities of various antioxidant enzymes viz., CAT, POD, SOD, that eventually improved growth, carbonic anhydrase activity, photosynthetic efficiency (Fariduddin et al., 2013b). Seed priming with $5.0 \mu \mathrm{M} \mathrm{L}^{-1} \mathrm{BL}$ was reported to improve the seed germination and seedling growth of 3 lucerne (Medicago sativa L.) varieties, viz., Victoria, Golden Empress, and Victor by significantly increasing the activities of POD, SOD, and CAT under salt stress (13.6 $\mathrm{dS} / \mathrm{m} \mathrm{NaCl}$ solution) (Zhang et al., 2007).

In salinity $(120 \mathrm{mM} \mathrm{NaCl})$ exposed IR-28 Oryza sativa seedlings, 24-EpiBL considerably alleviated oxidative damage and improved seedling growth by increasing APX activity and reducing lipid peroxidation (Özdemir et al., 2004). A polyhydroxylated spirostanic brassinosteroid analog (BB-16; 0.001 or $0.01 \mathrm{mg}$ $\left.\mathrm{dm}^{-3}\right)$ application to salinity $(75 \mathrm{~m} \mathrm{NaCl})$-exposed $O$. sativa seedlings showed significant increases in the activities of CAT, SOD, and GR (Nunez et al., 2003). Exogenous application of
24-epiBL to Oryza sativa var Pusa Basmati-1, grown under salt stress conditions exhibited improvement in growth, levels of protein, proline contents and antioxidant enzymes activities through expression of various BRs (OsBRI1, OsDWF4) and salt (SalT) responsive genes (Sharma et al., 2013b). Eggplant seedlings, when exposed to $90 \mathrm{mM} \mathrm{NaCl}$ with $0,0.025,0.05,0.10$, and $0.20 \mathrm{mg}$ $\mathrm{dm}^{-3}$ of epiBL for 10 days exhibited decreased electrolyte leakage, superoxide production, $\mathrm{MDA}, \mathrm{H}_{2} \mathrm{O}_{2}$ probably as a result of increased activities of SOD, GPX, CAT and APX enzymes and the contents of non-enzymatic antioxidants such as AsA and GSH (Ding et al., 2012). 24-epiBL decreased the adverse effects of salinity stress on two varieties of pepper (Capsicum annuum) arguably by increasing the activities of antioxidative enzymes and the contents of proline, total anthocyanins and minerals (Abbas et al., 2013). Spraying of $1.0 \mu \mathrm{M}$ of 24 -epiBL to $\mathrm{NaCl}$-exposed Brassica junceadetoxified the stress generated by $\mathrm{NaCl}$ by enhancing antioxidative enzymes and the level of proline (Ali et al., 2008 b). Supplementation of Vigna radiata c.v. T-44 plants with 28 -homoBL detoxified the stress generated by $\mathrm{NaCl}$ by elevating the activities of antioxidative enzymes and the proline content that in turn improved the MSI, leaf water potential $(\psi)$ (Hayat et al., 2010b). In a similar study, Rady (2011) reported that spraying $5 \mu \mathrm{M}$ of 24-epiBL to $\mathrm{NaCl}$-exposed Phaseolus vulgaris improved the MSI, RLWC as a result of significant elevations in the activities of antioxidative enzymes and proline content. Imbibition with 24-epiBL to pea (Pisum sativum L.) cv. climax seeds, subjected to sodium chloride stress significantly elevated the activity of SOD, POD, and CAT enzymes the helped plants to improve fresh and dry biomass, seedling height, photosynthetic rate, stomatal conductance, and the total chlorophyll content (Shahid et al., 2011). Treatment with 0.05 ppm BL as foliar spray mitigated salt stress-impacts in cowpea (Vigna sinensis) by inducing the activities of antioxidant enzymes such as SOD, POD, PPO and GR and the contents of AsA (El-Mashad and Mohamed, 2012).

\section{OTHER ABIOTIC STRESSES}

Apart from the discussed above major abiotic factors, BRs and associated compounds can also play significant roles in plants under a range of other abiotic stress factors such as photoinhibition/light stress, waterlogging/flooding stress, pesticides, neonicotinoid insecticide, imidacloprid (IMI) etc. (Kang et al., 2006, 2009; Lu et al., 2006; Xia et al., 2006, 2009a,b; Liang and Liang, 2009; Hayat et al., 2010c; Ogweno et al., 2010; Ahammed et al., 2012c; Lu and Guo, 2013; Sharma et al., 2013a,b). 24-BL (0.01 $\left.\mathrm{mg} \mathrm{l}^{-1}\right)$ has been benefitted tomato (Lycopersicon esculentum Mill.) to maintain net photosynthetic rate $(\mathrm{Pn})$, quantum efficiency of PSII ( $\Phi_{\text {PSII }}$ ) and photochemical quenching ( $\left.q \mathrm{P}\right)$ under photoinhibition/light stress by decreasing lipid peroxidation as a result of efficient ROS-metabolism via enhanced activity of SOD, GPX, CAT, and APX enzymes (Ogweno et al., 2010). In another study, exogenous application of 24-epiBL was reported to enhance the tolerance of elite Indica $O$. sativa variety (Pusa Basmati-1 seedlings) to stress generated by neonicotinoid insecticide, imidacloprid (IMI) by elevating the activity of antioxidative enzyme such as SOD, APX, CAT, GR and MDHAR, upregulating the expression of most of the genes like $\mathrm{Cu} / \mathrm{Zn}-\mathrm{SOD}$, 
Fe-SOD, Mn-SOD, APX, CAT and GR, and decreasing lipid peroxidation (Sharma et al., 2013a). In $80 \mathrm{mM} \mathrm{Ca}\left(\mathrm{NO}_{3}\right)_{2}$-exposed Cucumis sativus cv. Jinyou No. 4, EpiBL $(0.1 \mu \mathrm{M})$ protected the photosynthetic membrane system by up-regulating the ROSscavenging capacity of the antioxidant system (Yuan et al., 2012). Folair spray of epiBL or homoBL to Lycopersicon esculentum Mill. cv. K-21 showed lowered sodium nitroprusside (SNP) concentration $\left(10^{-5} \mathrm{M}\right)$ and improved growth and the content of pigment contents via strengthning antioxidant system (Hayat et al., 2010c). Application of 24-epiBL-mediated increased $\mathrm{H}_{2} \mathrm{O}_{2}$-metabolism and decreased lipid peroxidation via enhanced activity of GST and the content of GSH were argued to help Solanum lycopersicum seedlings to counteract three-ringed PAH (phenanthrene-PHE)-accrued consequences (Ahammed et al., 2012a,c). Alleviation of impacts caused by phenanthrene and pyrene phytotoxicity in tomato plants has been evidenced as a result of 24-epiBL-mediated increased activities of GPX, CAT, APX and GR and decreased content of MDA) (Ahammed et al., 2012b). Recently, these authors reported that 24-epiBL $(100 \mu \mathrm{M})$ can alleviate PCB (polychlorinated biphenyls)-induced oxidative stress in tomato plants by enhancing the activities of antioxidant enzymes, and maintaining photochemical efficiency of PSII $\mathrm{Fv} / \mathrm{Fm}$ ), the quantum efficiency of PSII photochemistry $[\Phi(\mathrm{PSII})]$ and photochemical quenching coefficient $(\mathrm{Pq})$ (Ahammed et al., 2013b). The 24-epiBL-mediated strengthning of antioxidant defense system and eventually decreased membrane lipid peroxidation was reported in plants exposed to phenanthrene + Cd co-contamination (Ahammed et al., 2013a). Pretreatment of Cucumis sativus with 24-epiBL alleviated the phytotoxicities of nine pesticides (paraquat, fluazifop-p-butyl, haloxyfop, flusilazole, cuproxat, cyazofamid, imidacloprid, chlorpyrifos, and abamectin) by increasing the activities of antioxidant enzymes, and $\mathrm{CO}_{2}$ assimilation capacity (Xia et al., 2006). Significant role of 24-epiBL was also reported in plants exposed to Chlorpyrifos (a widely used insecticide), where elevated activity of GST, POD, and GR was argued to regulate net photosynthetic rate and quantum yield of PSII [Phi(PSII)] (Xia et al., 2009a). BRs and associated compounds were reported to provide tolerance to waterlogging/flooding stress in different crops including soybean (Lu et al., 2006), cucumber (Kang et al., 2006, 2009; Lu and Guo, 2013) and oilseed rape (Liang and Liang, 2009) mainly as a result of decreased oxidative damage via enhanced activities of SOD and POD.

\section{CONCLUSION AND FUTURE PROSPECTS}

It is a well-established fact that environmental stresses are the primary cause of crop loss worldwide, reducing average yields for most major crop plants adversely affecting the global crop production and the adverse impacts are getting more serious in the past few decades. Environmental stresses induce the production of ROS, alter the activity of antioxidant system and adversely affect the process of photosynthesis. The crop physiologists and scientists have employed strategies to mitigate the elevated ROS (and their reaction products)-accrued oxidative stresses/damages via strengthening antioxidant defense system in plants exposed to various abiotic/stress factors. In this regard, the use of different plant growth regulators (PGRs) has been considered as a better sustainable alternative, and also as a technically simpler approach (Khan et al., 2012; Iqbal et al., 2013; Asgher et al., 2014). To this end, in addition to playing significant roles under general plant growth, development and metabolism, BRs and associated compounds have been extensively reported to counteract consequences of various abiotic stresses including temperature (heat, chilling, and freezing), water (drought, water logging), salt, heavy metals, light (intense and weak) and radiation (UV-A/B). Though much has been achieved in the current context, integrated approach is required to investigate more insights into molecular-genetic mechanisms of BRs and associated compounds-mediated modulation of various components of antioxidant defense system and subsequently the control of abiotic stress-consequences in plants.

\section{ACKNOWLEDGMENTS}

Financial support to B. V. Vardhini from University Grants Commission (UGC), New Delhi [MRP-655/05 (UGC-SERO); Link No 1655.0] India is gratefully acknowledged. Naser A. Anjum gratefully acknowledges the partial financial support received from Portuguese Foundation for Science and Technology (FCT) through post-doctoral research grants (SFRH/BPD/64690/2009; SFRH/BPD/84671/2012), and the Aveiro University Research Institute/Centre for Environmental and Marine Studies (CESAM).

\section{REFERENCES}

Abbas, S., Latif, H. H., and Elsherbiny, E. A. (2013). Effect of 24-epibrassinolide on the physiological and genetic changes on two varieties of pepper under salt stress conditions. Pak. J. Bot. 45, 1273-1284.

Aghdam, M. S., Asghari, M., Farmani, B., Mohayeji, M., and Moradbeygi, H. (2012). Impact of postharvest brassinosteroids treatment on PAL activity in tomato fruit in response to chilling stress. Sci. Hort. 144, 116-120. doi: 10.1016/j.scienta.2012.07.008

Aghdam, M. S., and Mohammadkhani, N. (2014). Enhancement of chilling stress tolerance of tomato fruit by postharvest brassinolide treatment. Food Bioproc. Technol. 7, 909-914. doi: 10.1007/s11947-013-1165-x

Ahammed, G. J., Choudhary, S. P., Chen, S., Xia, X., Shi, K., Zhou, Y., et al. (2013a). Role of brassinosteroids in alleviation of phenanthrene-cadmium co-contamination-induced photosynthetic inhibition and oxidative stress in tomato. J. Exp. Bot. 64, 199-213. doi: 10.1093/jxb/ers323

Ahammed, G. J., Gao, C. J., Ogweno, J. O., Zhou, Y. H., Xia, X. J., Mao, W. H., et al. (2012a). Brassinosteroids induce plant tolerance against phenanthrene by enhancing degradation and detoxification in Solanum lycopersicum L. Ecotoxicol. Environ. Saf. 80, 28-36. doi: 10.1016/j.ecoenv.2012.02.004

Ahammed, G. J., Ruan, Y. P., Zhou, J., Xia, X. J., Shi, K., Zhou, Y. H., et al. (2013b). Brassinosteroid alleviates polychlorinated biphenyls-induced oxidative stress by enhancing antioxidant enzymes activity in tomato. Chemosphere 90, 2645-2653. doi: 10.1016/j.chemosphere.2012.11.041

Ahammed, G. J., Yuan, H. L., Ogweno, J. O., Zhou, Y. H., Xia, X. J., Mao, W. H., et al. (2012b). Brassinosteroid alleviates phenanthrene and pyrene phytotoxicity by increasing detoxification activity and photosynthesis in tomato. Chemosphere 86, 546-555. doi: 10.1016/j.chemosphere.2011.10.038

Ahammed, G. J., Zhang, S., Shi, K., Zhou, Y. H., and Yu, J. Q. (2012c). Brassinosteroid improves seed germination and early development of tomato seedling under phenanthrene stress. Plant Growth Regul. 68, 87-96. doi: 10.1007/s10725-012-9696-0

Ahmed, M. A., and Shalaby, M. A. F. (2013). Physiological role of brassinolide in improving yield of six wheat cultivars (Triticum aestivum L.) grown under newly reclaimed sandy soil. J. Appl. Sci. Res. 9, 6387-6393.

Alam, M. M., Hayat, S., Ali, B., and Ahmad, A. (2007). Effect of 28homobrassinolide treatment on nickel toxicity in Brassica juncea. Photosynthetica 45, 139-142. doi: 10.1007/s11099-007-0022-4 
Ali, B., Hasan, S. A., Hayat, S., Hayat, Q., Yadav, S., Fariduddin, Q., et al. (2008b). A role for brassinosteroids in the amelioration of aluminium stress through antioxidant system in mung bean (Vigna radiata L. Wilczek). Environ. Exp. Bot. 62, 153-159. doi: 10.1016/j.envexpbot.2007.07.014

Ali, B., Hayat, S., and Ahmad, A. (2007). 28-Homobrassinolide ameliorates the saline stress in chickpea (Cicer arietinum L.). Environ. Exp. Bot. 59, 217-223. doi: 10.1016/j.envexpbot.2005.12.002

Ali, B., Hayat, S., Fariduddin, Q., and Ahmad, A. (2008a). 24-Epibrassinolide protects against the stress generated by salinity and nickel in Brassica juncea. Chemosphere 72, 1387-1392. doi: 10.1016/j.chemosphere.2008. 04.012

Ali, Q., Athar, H. U. R., and Ashraf, M. (2006). Influence of exogenously applied brassinosteroids on the mineral nutrient status of two wheat cultivars grown under saline conditions. Pak. J. Bot. 38, 1621-1632.

Alyemeni, M. N., Hayat, S., Wijaya, L., and Anaji, A. (2013). Foliar application of 28-homobrassinolide mitigates salinity stress by increasing the efficiency of photosynthesis in Brassica juncea. Acta Bot. Bras. 27, 502-505. doi: 10.1590/S0102-33062013000300007

Anjum, N. A., Sofo, A., Scopa, A., Roychoudhury, A., Gill, S. S., Iqbal, M., et al. (2014). Lipids and proteins - major targets of oxidative modifications in abiotic stressed plants. Environ. Sci. Pollut. Res. doi: 10.1007/s11356-014-3917-1. [Epub ahead of print].

Anjum, N. A., Umar, S., and Chan, M. T. (2010). Ascorbate-Glutathione Pathway and Stress Tolerance in Plants. Dordrecht: Springer.

Anjum, N. A., Umar, S., and Ahmad, A. (2012). Oxidative Stress in Plants: Causes, Consequences and Tolerance. New Delhi: IK International Publishing House.

Anjum, S. A., Wang, L. C., Farooq, M., Hussain, M., Xue, L. L., and Zou, C. M. (2011). Brassinolide application improves the drought tolerance in maize through modulation of enzymatic antioxidants and leaf gas exchange. J. Agron. Crop Sci. 197, 177-185. doi: 10.1111/j.1439-037X.2010.00459.x

Anuradha, S., and Rao, S. S. R. (2007a). Effect of 24-epibrassinolide on the growth and antioxidant enzyme activities in radish seedlings under lead toxicity. Indian J. Plant Physiol. 12, 396-400.

Anuradha, S., and Rao, S. S. R. (2007b). The effect of brassinosteroids on radish (Raphanus sativus L.) seedlings growing under cadmium stress. Plant Soil Environ. 53, 465-472.

Anuradha, S., and Rao, S. S. R. (2009). Effect of 24-epibrassinolide on the photosynthetic activity of radish plants under cadmium stress. Photosynthetica 47, 317-320. doi: 10.1007/s11099-009-0050-3

Arora, N., Bhardwaj, R., Sharma, P., and Arora, H. K. (2008a). Effects of 28homobrassinolide on growth, lipid peroxidation and antioxidative enzyme activities in seedlings of Zea mays L. under salinity stress. Acta Physiol. Plant 30, 833-839. doi: 10.1007/s11738-008-0188-9

Arora, N., Bhardwaj, R., Sharma, P., Arora, H. K., and Arora, P. (2008b). Amelioration of zinc toxicity by 28 -homobrassinolide in Zea mays L. Can. J. Pure Appl. Sci. 2, 503-509.

Arora, P., Bhardwaj, R., and Kanwar, M. K. (2010a). 24-Epibrassinolide induced antioxidative defense system of Brassica juncea L. under Zn metal stress. Physiol. Mol. Biol. Plant 16, 285-293. doi: 10.1007/s12298-010-0031-9

Arora, P., Bhardwaj, R., and Kanwar, M. K. (2010b). 24-Epibrassinoliide regulated diminution of Cr metal toxicity in Brassica juncea L. plants. Braz. J. Plant Physiol. 22, 159-165. doi: 10.1590/S1677-04202010000300002

Arora, P., Bhardwaj, R., and Kanwar, M. K. (2012). Effect of 24-epibrassinolide on growth, protein content and antioxidative defense system of Brassica juncea L. subjected to cobalt ion toxicity. Acta Physiol. Plant 34, 2007-2017. doi: 10.1007/s11738-012-1002-2

Arteca, J. M., and Arteca, R. N. (2001). Brassinosteroid-induced exaggerated growth in hydroponically grown Arabidopsis plants. Physiol. Plant 112, 104-112. doi: 10.1034/j.1399-3054.2001.1120114.x

Asami, T., Mink, Y. K., Nagata, N., Yamagishi, K., Takatsuto, S., Fujioka, S., et al. (2000). Characterization of brassinozole, a triazole-type brassinosteroid biosynthesis inhibitor. Plant Physiol. 123, 93-100. doi: 10.1104/pp.123.1.93

Asgher, M., Khan, M. I. R., Anjum, N. A., and Khan, N. A. (2014). Minimizing toxicity of cadmium in plants - role of plant growth regulators. Protoplasma. doi: 10.1007/s00709-014-0710-4. [Epub ahead of print].

Ashraf, M., Akram, N. A., Arteca, R. N., and Foolad, M. R. (2010). The physiological, biochemical and molecular roles of brassinosteroids and salicylic acid in plant processes and salt tolerance. Critic. Rev. Plant Sci. 29, 162-190. doi: $10.1080 / 07352689.2010 .483580$
Avalbaev, A. M., Yuldashev, R. A., Fatkhutdinova, R. A., Urusov, F. A., Safutdinova, Y. V., and Shakirova, F. M. (2010). The influence of 24-epibrassinolide on the hormonal status of wheat plants under sodium chloride. Appl. Biochem. Microbiol. 46, 99-102. doi: 10.1134/S0003683810010175

Aydin, Y., Talas-Ogras, T., Ipekci-Altas, Z., and Gozukirmizi, N. (2006). Effects of brassinosteroid on cotton regeneration via somatic embryogenesis. Biologia (Bratislava) 61, 289-293. doi: 10.2478/s11756-006-0053-5

Bajguz, A. (2009). Brassinosteroid enhanced the level of abscisic acid in Chlorella vulgaris subjected to short-term heat stress. J. Plant Physiol. 166, 882-886. doi: 10.1016/j.jplph.2008.10.004

Bajguz, A. (2010). An enhancing effect of exogenous brassinolide on the growth and antioxidant activity in Chlorella vulgaris cultures under heavy metals stress. Environ. Exp. Bot. 68, 175-179. doi: 10.1016/j.envexpbot.2009. 11.003

Bajguz, A., and Piotrowska-Niczyporuk, A. (2014). Interactive effect of brassinosteroids and cytokinins on growth, chlorophyll, monosaccharide and protein content in the green alga Chlorella vulgaris (Trebouxiophyceae). Plant Physiol. Biochem. 80C, 176-183. doi: 10.1016/j.plaphy.2014.04.009

Behnamnia, M., Kalantari, K. M., and Rezanejad, F. (2009). Exogenous application of brassinosteroid alleviates drought-induced oxidative stress in Lycopersicon esculentum L. Gen. Appl. Plant Physiol. 35, 22-34.

Bishop, G. J., and Yakota, T. (2001). Plant steroid hormones, brassinosteroids: current highlights of molecular aspects on their synthesis,/metabolism, transport, perception and response. Plant Cell Physiol. 42, 114-120. doi: $10.1093 / \mathrm{pcp} / \mathrm{pce} 018$

Borcioni, E., and Bonato-Negrelle, R. R. (2012). Application of analogue brassinosteroide (Biobras $16(\mathrm{R})$ ) germination and growth in vitro culture of zygotic embryos and acclimatization of bocaiuva. Ciencia Rural. 42, 270-275.

Bray, E. A., Bailey-Serres, J., and Weretilnyk, E. (2000). "Responses to abiotic stresses," in Biochemistry and Molecular Biology of Plants, eds W. Gruissem, B. Buchnnan, and R. Jones (Rockville, MD: American Society of Plant Physiologists), 1158-1249.

Cao, Y. Y., and Zhao, H. (2007). Protective roles of brassinolide in rice seedlings under heat stress. Zhongguo Shuidao Kexue (China Rice Science) 21, 525-529.

Carange, J., Longpré, F., Daoust, B., and Martinoli, M. G. (2011). 24Epibrassinolide, a phytosterol from the brassinosteroid family, protects dopaminergic cells against $\mathrm{MPP}^{+}$-induced oxidative stress and apoptosis. J. Toxicol. 2011:392859. doi: 10.1155/2011/392859

Cheng, Y., Zhu, W., Chen, Y., Ito, S., Asami, T., and Wang, X. (2014). Brassinosteroids control root epidermal cell fate via direct regulation of a MYB-bHLH-WD40 complex by GSK3-like kinases. eLife 3:e02525. doi: 10.7554/eLife.02525

Choudhary, S. P., Kanwar, M., Bhardwaj, R., Gupta, B. D., and Gupta, R. K. (2011). Epibrassinolide ameliorates Cr (VI) stress via influencing the levels of indole-3-acetic acid, abscisic acid, polyamines and antioxidant system of radish seedlings. Chemosphere 84, 592-600. doi: 10.1016/j.chemosphere.2011. 03.056

Creelman, R. A., and Mullet, J. E. (1997). Oligosaccharins, brassinolides, and jasmonates: nontraditional regulators of plant growth, development, and gene expression. Plant Cell 9, 1211-1223. doi: 10.1105/tpc.9.7.1211

Dalio, R. J. D., Pinheiro, H. P., Sodek, L., and Haddad, C. R. B. (2013). 24Epibrassinolide restores nitrogen metabolism of pigeon pea under saline stress. Bot. Stud. 54:9. doi: 10.1186/1999-3110-54-9

Das, T., Shukla, Y. M., Poonia, T. C., Meena, M., and Meena, M. D. (2013). Effects of brassinolide on physiological characteristics of rice (Oryza sativa L.) with different salinity levels. Ann. Biol. 29, 228-231.

Daur, I., and Tatar, O. (2013). Effects of gypsum and brassinolide on soil properties, and berseem (Trifolium alexandrinum L.) growth, yield and chemical composition grown on saline soil. Legume Res. 36, 306-311.

Deng, Z. P., Zhang, X., Tang, W. Q., Oses-Prieto, J. A., Suzuki, N., Gendron, J. M., et al. (2007). A proteomics study of brassinosteroid response in Arabidopsis. Mol. Cell. Proteomics 6, 2058-2071. doi: 10.1074/mcp.M700123-MCP200

Ding, H. D., Zhu, X. H., Zhu, Z. W., Yang, S. J., Zha, D. S., and Wu, X. X. (2012). Amelioration of salt-induced oxidative stress in eggplant by application of 24-epibrassinolide. Biol. Plant 56, 767-770. doi: 10.1007/s10535-01 2-0108-0

Divi, U. K., and Krishna, P. (2010). Overexpression of the brassinosteroid biosynthetic gene AtDWF4 in Arabidopsis seeds overcomes abscisic acid-induced 
inhibition of germination and increases cold tolerance in transgenic seedlings. J. Plant Growth Regul. 29, 385-393. doi: 10.1007/s00344-0109150-3

Divi, U. K., Rahman, T., and Krishna, P. (2010). Brassinosteroid-mediated stress tolerance in Arabidopsis shows interactions with abscisic acid, ethylene and salicylic acid pathways. BMC Plant Biol. 10:151. doi: 10.1186/1471-222 9-10-151

Domagalska, M. A., Sarnowska, E., Nagy, F., and Davis, S. J. (2010). Genetic analyses of interactions among gibberellin, abscisic acid, and brassinosteroids in the control of flowering time in Arabidopsis thaliana. PLOS ONE 5:e14012. doi: 10.1371/journal.pone.0014012

Dong, D., Li, Y., and Jiang, L. (2008). Effects of brassinosteroids on photosynthetic characteristics in soybean under aluminum stress. Zuowu Xuebao (Acta Agronomica Sinica) 34, 1673-1678. doi: 10.3724/SP.J.1006.2008. 01673

Durigan, D. R. J., Pinheiro, H. P., Sodek, L., and Haddad, C. R. B. (2011). The effect of 24-epibrassinolide and clotrimazole on the adaptation of Cajanus cajan (L.) Millsp to salinity. Acta Physiol. Plant 33, 1887-1896. doi: 10.1007/s11738-0110732-x

Ekinci, M., Yildirim, E., Dursun, A., and Turan, M. (2012). Mitigation of salt stress in lettuce (Lactuca sativa L. var. Crispa) by seed and foliar 24-epibrassinolide treatments. Hortic. Sci. 47, 631-636.

El-Khallal, S. M. (2002). The influence of some phyto-growth regulators on the activity of antioxidant system in maize plant under water stressed conditions. Bull. Faculty Sci. Assiut. Univ. D Bot. 31, 183-197.

El-Khallal, S. M., Hathout, T. A., Ashour, A. E. R. A., and Kerrit, A. A. A. (2009). Brassinolide and salicylic acid induced antioxidant enzymes, hormonal balance and protein profile of maize plants grown under salt stress. Res. J. Agric. Biol. Sci. 5, 391-402.

El-Mashad, A., and Mohamed, H. (2012). Brassinolide alleviates salt stress and increases antioxidant activity of cowpea plants (Vigna sinensis). Protoplasma 249, 625-635. doi: 10.1007/s00709-011-0300-7

Fábregas, N., and Caño-Delgado, A. I. (2014). Turning on the microscope turret: a new view for the study of brassinosteroid signaling in plant development. Physiol. Plant 151, 172-183. doi: 10.1111/ppl.12130

Fariduddin, Q., Khalil, R. R. A. E., Mir, B. A., Yusuf, M., and Ahmad, A. (2013a). 24-Epibrassinolide regulates photosynthesis, antioxidant enzyme activities and proline content of Cucumis sativus under salt and/or copper stress. Environ. Monit. Assess. 185, 7845-7856. doi: 10.1007/s10661-013-3139-x

Fariduddin, Q., Khanam, S., Hasan, S. A., Ali, B., Hayat, S., and Ahmad, A. (2009a). Effect of 28-homobrassinolide on the drought stress-induced changes in photosynthesis and antioxidant system of Brassica juncea L. Acta Physiol. Plant 31, 889-897. doi: 10.1007/s11738-009-0302-7

Fariduddin, Q., Mir, B. A., Yusuf, M., and Ahmad, A. (2013b). Comparative roles of brassinosteroids and polyamines in salt stress tolerance. Acta Physiol. Plant 35, 2037-2053. doi: 10.1007/s11738-013-1263-4

Fariduddin, Q., Yusuf, M., Chalkoo, S., Hayat, S., and Ahmad, A. (2011). 28Homobrassinolide improves growth and photosynthesis in Cucumis sativus L. through an enhanced antioxidant system in the presence of chilling stress. Photosynthetica 49, 55-64. doi: 10.1007/s11099-011-0022-2

Fariduddin, Q., Yusuf, M., Hayat, S., and Ahmad, A. (2009b). Effect of 28homobrassinolide on antioxidant capacity and photosynthesis in Brassica juncea plants exposed to different levels of copper. Environ. Exp. Bot. 66, 418-424. doi: 10.1016/j.envexpbot.2009.05.001

Farooq, M., Wahid, A., Lee, D. J., Cheema, S. A., and Aziz, T. (2010). Comparative time course action of the foliar applied glycinebetaine, salicylic acid, nitrous oxide, brassinosteroids and spermine in improving drought resistance of rice. J. Agron. Crop Sci. 196, 336-345. doi: 10.1111/j.1439-037X.2010.00422.x

Fedina, E. O. (2013). Effect of 24-epibrassinolide on pea protein tyrosine phosphorylation after salinity action. Russ. J. Plant Physiol. 60, 351-358. doi: 10.1134/S1021443713020088

Filova, A., Sytar, O., and Krivosudska, E. (2013). Effects of brassinosteroid on the induction of physiological changes in Helianthus annuus L. under copper stress. Acta Universitatis Agriculturae et Silviculturae Mendelianae Brunensis 61, 623-629. doi: 10.11118/actaun201361030623

Friedrichsen, D. M., Nemhauser, J., Muramitsu, T., Maloof, N. N., Alonso, J., Ecker, J. R., et al. (2002). Three redundant brassinosteroids early response genes encode putative bHLH transcription factors required for normal growth. Genetics 162, 1445-1456.
Gao, W., Long, L., Zhu, L., Xu, L., Gao, W. H., Sun, L. Q., et al. (2013). Proteomic and virus-induced gene silencing (VIGS) analyses reveal that gossypol, brassinosteroids and jasmonic acid contribute to the resistance of cotton to Verticillium dahliae. Mol. Cell. Proteomics 12, 3690-3703. doi: 10.1074/mcp.M113.031013

Gill, S. S., and Tuteja, N. (2010). Reactive oxygen species and antioxidant machinery in abiotic stress tolerance in crop plants. Plant Physiol. Biochem. 48, 909-930. doi: 10.1016/j.plaphy.2010.08.016

Gomes, M. M. A., Torres Netto, A., Campostrini, E., Bressan-Smith, R., Zullo, M. A. T., Ferraz, T. M., et al. (2013). Brassinosteroid analogue affects the senescence in two papaya genotypes submitted to drought stress. Theor. Exp. Plant Physiol. 25, 186-195. doi: 10.1590/S2197-00252013000300003

González-Garcia, M. P., Vilarrasa-Blasi, J., Zhiponova, M., Divol, F., Mora-Garcia, S., Russinova., E., et al. (2011). Brassinosteroids control meristem size by promoting cell cycle progression in Arabidopsis roots. Development 138, 849-859. doi: 10.1242/dev.057331

Grove, M. D.,Spencer, G. F., Rohwededer, W. K., Mandava, N. B., Worlet, J. F., and Warthen, J. C. Jr., et al. (1979). Brassinolide, a plant promoting steroid isolated from Brassica napus pollen. Nature 281, 121-124. doi: 10.1038/ $281216 \mathrm{a} 0$

Hartwig, T., Chuck, G. S., Fujioka, S., Klempien, A., Weizbauer, R., Potluri, D. P. V., et al. (2011). Brassinosteroid control of sex determination in maize. Proc. Natl. Acad. Sci. U.S.A. 108, 19814-19819. doi: 10.1073/pnas. 1108359108

Hasan, S. A., Hayat, S., and Ahmad, A. (2011). Brassinosteroids protect photosynthetic machinery against the cadmium induced oxidative stress in two tomato cultivars. Chemosphere 84, 1446-1451. doi: 10.1016/j.chemosphere.2011.04.047

Hasan, S. A., Hayat, S., Ali, B., and Ahmad, A. (2008). 28-Homobrassinolide protects chickpea (Cicer arietinum) from cadmium toxicity by stimulating antioxidants. Environ. Pollut. 151, 60-66. doi: 10.1016/j.envpol.2007.03.006

Haubrick, L. L., and Assmann, S. M. (2006). Brassinosteroids and plant function: some clues, more puzzles. Plant Cell Environ. 29, 446-457. doi: 10.1111/j.13993054.2006.00708.x

Haubrick, L. L., Torsethaugen, G., and Assmann, S. M. (2006). Effect of bassinolide, alone and in concert with abscisic acid, on control of stomatal aperture and potassium currents of Vicia faba guard cell protoplasts. Physiol. Plant 128, 134-143. doi: 10.1111/j.1399-3054.2006.00708.x

Hayat, S., Ali, B., Hasan, S. A., and Ahmad, A. (2007). Brassinosteroid enhanced the level of antioxidants under cadmium stress in Brassica juncea. Environ. Exp. Bot. 60, 33-41. doi: 10.1016/j.envexpbot.2006.06.002

Hayat, S., Alyemeni, M., and Hasan, S. (2012). Foliar spray of brassinosteroid enhances yield and quality of Solanum lycopersicum under cadmium stress. Saudi J. Biol. Sci. 19, 325-335. doi: 10.1016/j.sjbs.2012.03.005

Hayat, S., Hasan, S. A., Hayat, Q., and Ahmad, A. (2010a). Brassinosteroids protect Lycopersicon esculentum from cadmium toxicity applied as shotgun approach. Protoplasma 239, 3-14. doi: 10.1007/s00709-009-0075-2

Hayat, S., Hasan, S. A., Yusuf, M., Hayat, Q., and Ahmad, A. (2010b). Effect of 28 homobrassinolide on photosynthesis, fluorescence and antioxidant system in the presence or absence of salinity and temperature in Vigna radiata. Environ. Exp. Bot. 69, 105-112. doi: 10.1016/j.envexpbot.2010.03.004

Hayat, S., Yadav, S., Ali, B., and Ahmad, A. (2010c). Interactive effect of nitric oxide and brassinosteroids on photosynthesis and the antioxidant system of Lycopersicon esculentum. Russ. J. Plant Physiol. 57, 212-221. doi: $10.1134 /$ S1021443710020081

Ho, M. O. (2003). Brassinosteroids accelerate the rate of cell division in isolated protoplasts of Petunia hybrida. J. Plant Biotechnol. 5, 63-67.

Hu, C. H., Guo, J., Chen, L., Li, J. P., Qiao, L., and He, L. (2014). Influence of exogenous brassinolide on growth and resistance of maize seedling with preservative stress. Hunan Nongye Daxue Xuebao 40, 113-116. doi: 10.1007/s11099-0100071-y

Hu, W. H., Wu, Y., Zeng, J. Z., He, L., and Zeng, Q. M. (2010). Chill-induced inhibition of photosynthesis was alleviated by 24-epibrassinolide pretreatment in cucumber during chilling and subsequent recovery. Photosynthetica 48, 537-544. doi: 10.1007/s11099-010-0071-y

Hu, W. H., Yan, X. H., Xiao, Y. A., Zeng, J. J., Qi, H. J., and Ogweno, J. O. (2013). 24-Epibrassinosteroid alleviate drought-induced inhibition of photosynthesis in Capsicum annuum. Sci. Hortic. 150, 232-237. doi: 10.1016/j.scienta.2012. 11.012

Huang, B., Chu, C. H., Chen, S. L., Juan, H. F., and Chen, Y. M. (2006). A proteomics study of the mung bean epicotyl regulated by brassinosteroids 
under conditions of chilling stress. Cell Mol. Biol. Lett. 11, 264-278. doi: 10.2478/s11658-006-0021-7

Iqbal, N., Trivellini, A., Masood, A., Ferrante, A., and Khan, N. A. (2013). Current understanding on ethylene signaling in plants: the influence of nutrient availability. Plant Physiol. Biochem. 73, 128-138. doi: 10.1016/j.plaphy.201 3.09.011

Janeczko, A., Gullner, G., Skoczowski, A., Dubert, F., and Barna, B. (2007). Effects of brassinosteroid infiltration prior to cold treatment on ion leakage and pigment contents in rape leaves. Biol. Plant 51, 355-358. doi: 10.1007/s10535-00 7-0072-2

Janeczko, A., Hura, K., Skoczowski, A., Idzik, I., Biesaga-Koscielniak, J., and Niemczyk, E. (2009). Temperature-dependent impact of 24-epibrassinolide on the fatty acid composition and sugar content in winter oilseed rape callus. Acta Physiol. Plant 31, 71-79. doi: 10.1007/s11738-008-0202-2

Janeczko, A., Koscielniak, J., Pilipowicz, M., Szarek-Lukaszewska, G., and Skoczowski, A. (2005). Protection of winter rape photosystem 2 by 24 epibrassinolide under cadmium stress. Photosynthetica 43, 293-298. doi: 10.1007/s11099-005-0048-4

Janeczko, A., Oklestkova, J., Pociecha, E., Koscielniak, J., and Mirek, M. (2011). Physiological effects and transport of 24-epibrassinolide in heat-stressed barley. Acta Physiol. Plant 33, 1249-1259. doi: 10.1007/s11738-010-0655-y

Jiang, Y. P., Huang, L. F., Cheng, F., Zhou, Y. H., Xia, X. J., Mao, W. H., et al. (2013). Brassinosteroids accelerate recovery of photosynthetic apparatus from cold stress by balancing the electron partitioning, carboxylation and redox homeostasis in cucumber. Physiol. Plant 148, 133-145. doi: 10.1111/j.13993054.2012.01696.x

Jin, H., Do, J., Shin, S. J., Choi, J. W., Choi, Y. I., Kim, W., et al. (2014). Exogenously applied 24-epi brassinolide reduces lignification and alters cell wall carbohydrate biosynthesis in the secondary xylem of Liriodendron tulipifera. Phytochemistry 101, 40-51. doi: 10.1016/j.phytochem.2014.02.003

Kang, Y. Y., Guo, S. R., Duan, J. J., and Hu, X. H. (2006). Effects of 24epibrassinolide on antioxidant system and anaerobic respiratory enzyme activities in cucumber roots under hypoxia stress. J. Plant Physiol. Mol. Biol. 32, 535-542.

Kang, Y. Y., Guo, S. R., Li, J., and Duan, J. J. (2009). Effect of root applied 24epibrassinolide on carbohydrate status and fermentative enzyme activities in cucumber (Cucumis sativus L.) seedlings under hypoxia. Plant Growth Regul. 57, 259-269. doi: 10.1007/s10725-008-9344-x

Kanwar, M. K., Bhardwaj, R., Arora, P., Chowdhary, S. P., Sharma, P., and Kumar, S. (2012). Plant steroid hormones produced under Ni stress are involved in the regulation of metal uptake and oxidative stress in Brassica juncea L. Chemosphere 86, 41-49. doi: 10.1016/j.chemosphere.2011.08.048

Kanwar, M. K., Bhardwaj, R., Chowdhary, S. P., Arora, P., Sharma, P., and Kumar, S. (2013). Isolation and characterization of 24-epibrassinolide from Brassica juncea L. and its effects on growth, Ni ion uptake, antioxidant defense of Brassica plants and in vitro cytotoxicity. Acta Physiol. Plant 35, 1351-1362. doi: 10.1007/s11738-012-1175-8

Kapoor, D., Rattan, A., Gautam, V., Kapoor, N., and Bharadwaj, R. (2014). 24Epibrassinolide mediated photosynthetic pigments and antioxidative defense systems of radish seedling under cadmium and mercury stress. J. Stress Physiol. Biochem. 10, 110-121.

Karlidag, H., Yildirim, E., and Turan, M. (2011). Role of 24-epibrassinolide in mitigating the adverse effects of salt stress on stomatal conductance, membrane permeability, and leaf water content, ionic composition in salt stressed strawberry (Fragaria $x$ ananassa). Sci. Hort. 130, 133-140. doi: 10.1016/j.scienta.2011.06.025

Kartal, G., Temel, A., Arican, E., and Gozukirmizi, N. (2009). Effects of brassinosteroids on barley root growth, antioxidant system and cell division. Plant Growth Regul. 58, 261-267. doi: 10.1007/s10725-009-9374-z

Khan, N. A., Nazar, R., Iqbal, N., and Anjum, N. A. (2012). Phytohormones and Abiotic Stress Tolerance in Plants. Berlin; Heidelberg: Springer Verlag.

Kroutil, M., Hejtmankova, A., and Lachman, J. (2010). Effect of spring wheat (Triticum aestivum L.) treatment with brassinosteroids on the content of cadmium and lead in plant aerial biomass and grain. Plant Soil Environ. $56,43-50$.

Kumar, M., Sirhindi, G., Bhardwaj, R., Kumar, S., and Jain, G. (2010). Effect of exogenous $\mathrm{H}_{2} \mathrm{O}_{2}$ on antioxidant enzymes of Brassica juncea $\mathrm{L}$. seedlings in relation to 24-epibrassinolide under chilling stress. Indian J. Biochem. Biophys. 47, $378-382$.
Kurepin, L. V., Joo, S. H., Kim, S. K., Pharis, R. P., and Back, T. G. (2012). Interaction of brassinosteroids with light quality and plant hormones in regulating shoot growth of young sunflower and Arabidopsis seedlings. J. Plant Growth Regul. 31, 156-164. doi: 10.1007/s00344-011-9227-7

Kurepin, L. V., Qaderi, M. M., Back, T. G., Reid, D. M., and Pharis, R. P. (2008). A rapid effect of applied brassinolide on abscisic acid concentrations in Brassica napus leaf tissue subjected to short-term heat stress. Plant Growth Regul. 55, 165-167. doi: 10.1007/s10725-008-9276-5

Li, K. R., Wang, H. H., Han, G., Wang, Q. J., and Fan, J. (2008). Effects of brassinolide on the survival, growth and drought resistance of Robinia pseudoacacia seedlings under water-stress. New Forests 35, 255-266. doi: 10.1007/s11056-0079075-2

Li, K. R., and Feng, C. H. (2011). Effects of brassinolide on drought resistance of Xanthoceras sorbifolia seedlings under water stress. Acta Physiol. Plant 33, 1293-1300. doi: 10.1007/s11738-010-0661-0

Li, L., and Van Staden, J. (1998a). Effects of plant growth regulators on drought resistance of two maize cultivars. South Afr. J. Bot. 64, 116-120.

Li, L., and Van Staden, J. (1998b). Effects of plant growth regulators on the antioxidant system in callus of two maize cultivars subjected to water stress. Plant Growth Regul. 24, 55-66.

Li, L., Van Staden, J., and Jager, A. K. (1998). Effects of plant growth regulators on the antioxidant system in seedlings of two maize cultivars subjected to water stress. Plant Growth Regul. 25, 81-87. doi: 10.1023/A:10107747 25695

Li, Y. H., Liu, Y. J., Xu, X. L., Jin, M., An, L. Z., and Zhang, H. (2012b). Effect of 24-epibrassinolide on drought stress-induced changes in Chorispora bungeana. Biol. Plant 56, 192-196. doi: 10.1007/s10535-012-0041-2

Li, Z. Y., Xu, Z. S., He, G. Y., Yang, G. X., Chen, M., Li, L. C., et al. (2012a). A mutation in Arabidopsis BSK5 encoding a brassinosteroid-signaling kinase protein affects responses to salinity and abscisic acid. Biochem. Biophys. Res. Commun. 426, 522-527. doi: 10.1016/j.bbrc.2012.08.118

Liang, J., and Liang, Y. (2009). Effects of plant growth substances on water-logging resistance of oilseed rape seedling. Xinan Shifan Daxue Xuebao, Ziran Kexueban $34,58-62$.

Liu, H., Guo, T., Zhu, Y., Wang, C., and Kang, G. (2006). Effects of epi-brassinolide (epi-BR) application at anthesis on starch accumulation and activities of key enzymes in wheat grains. Acta Agron. Sinica 32, 924-930.

Liu, Y. J., Jiang, H. F., Zhao, Z. G., and An, L. Z. (2011). Abscisic acid is involved in brassinosteroids-induced chilling tolerance in the suspension cultured cells from Chorispora bungeana. J. Plant Physiol. 168, 853-862. doi: 10.1016/j.jplph.2010.09.020

Liu, Y. J., Zhao, Z. G., Si, J., Di, C. X., Han, J., and An, L. Z. (2009). Brassinosteroids alleviate chilling-induced oxidative damage by enhancing antioxidant defense system in suspension cultured cells of Chorispora bungeana. Plant Growth Regul. 59, 207-214. doi: 10.1007/s10725-009-9405-9

Lu, Z., Huang, M., Ge, D. P., Yang, Y. H., Cao, X. N., Qin, P., et al. (2003). Effect of brassinolide on callus growth and regeneration in Spartina patens (Poaceae). Plant Cell Tissue Org. Cult. 73, 87-89. doi: 10.1023/A:1022665210113

Lu, X. M., and Guo, S. R. (2013). Effects of brassinolide on the polyamines, ATPase activity and inorganic ion content in roots of cucumber seedlings under hypoxia stress. Shengtaixue Zazhi 32, 611-614.

Lu, X. M., and Yang, W. (2013). Alleviation effects of brassinolide on cucumber seedlings under $\mathrm{NaCl}$ stress. Ying Yong Sheng Tai Xue Bao 24, 1409-1414.

Lu, X., Chen, Y., Gong, W., and Chen, Y. (2006). Effect of brassinolide on the seedling growth and waterlogging resistance of soybean. Chinese Agric. Sci. Bull. $23,37-38$

Ma, N., Liu, D., Zhang, C., Li, J., and Li, G. (2009). Regulation effect of exogenous hormones on growth and photosynthesis and yield of rapeseed (Brassica napus L.) after frozen. Zuowu Xuebao (Acta Agronomica Sinica). 35, 1336-1343. doi: 10.3724/SP.J.1006.2009.01336

Mahesh, B., Parshavaneni, B., Ramakrishna, B., and Rao, S. S. R. (2013). Effect of brassinosteroids on germination and seedling growth of radish (Raphanus sativus L.) under PEG-6000 induced water stress. Am. J. Plant Sci. 4, 2305-2313. doi: 10.4236/ajps.2013.412285

Malabadi, R. B., and Nataraja, K. (2007). 24-Epibrassinolide induces somatic embryogenesis in Pinus wallichiana A. B. Jacks. J. Plant Sci. 2, 171-178. doi: 10.3923/jps.2007.171.178

Manzano, S., Martínez, C., Megías, Z., Gómez, P., Garrido, D., and Jamilena, M. (2011). The role of ethylene and brassinosteroids in the control of sex expression 
and flower development in Cucurbita pepo. Plant Growth Regul. 65, 213-221. doi: 10.1007/s10725-011-9589-7

Mazorra, L. M., Holton, N., Bishop, G. J., and Nunez, M. (2011). Heat shock response in tomato brassinosteroid mutants indicates that thermotolerance is independent of brassinosteroid homeostasis. Plant Physiol. Biochem. 49, 1420-1428. doi: 10.1016/j.plaphy.2011.09.005

Mazorra, L. M., Nunez, M., Hechavarria, M., Coll, F., and Sanchez-Blanco, M. J. (2002). Influence of brassinosteroids on antioxidant enzymes activity in tomato under different temperatures. Biol. Plant 45, 593-596. doi: 10.1023/A:1022390917656

Meudt, W. J., Thompson, M. T., and Bennett, H. W. (1983). Investigations on mechanism of the brassinosteroid response. III. Techniques for potential enhancement of crop production. Proc. Plant Growth Regul. Soc. Am. 10, 312-318.

Mitchell, J. W., Mandava, N. B., Worley, J. E., Plimmer, J. R., and Smith, M. V. (1970). Brassins: a family of plant hormones from rape pollen. Nature 225, 1065-1066. doi: 10.1038/2251065a0

Mousavi, E. A., Kalantari, K. M., and Jafari, S. R. (2009). Change of some osmolytes accumulation in water-stressed colza (Brassica napus L.) as affected by 24-epibrassinolide. Iranian J. Sci. Technol. Transac. A Sci. 33, 1-11.

Nagata, N., Asami, T., and Yoshida, S. (2001). Brassinozole, an inhibitor of brassinosteroids biosynthesis, inhibits development of secondary xylem in cress plants (Lepidium sativum). Plant Cell Biol. 42, 1006-1011. doi: 10.1093/pcp/ pce122

Nakaya, M., Tsukaya, H., Murakami, N., and Kato, M. (2002). Brassinosteroids control the proliferation of leaf cells of Arabidopsis thaliana. Plant Cell Physiol. 43, 239-244. doi: 10.1093/pcp/pcf024

Nomura, T., Nakayama, N., Reid, J. B., Takeuchi, Y., and Yokota, T. (1997). Blockage of brassinosteroid biosynthesis and sensitivity cause dwarfism in Pisum sativum. Plant Physiol. 113, 31-37.

Nunez, M., Mazzafera, P., Mazorra, L. M., Siqueira, W. J., and Zullo, M. A. T. (2003). Influence of a brassinosteroid analog on antioxidant enzymes in rice grown in culture medium with $\mathrm{NaCl}$. Biol. Plant 47, 67-70. doi: 10.1023/A:1027380831429

Ogweno, J. O., Hu, W. H., Song, X. S., Shi, K., Mao, W. H., Zhou, Y. H., et al. (2010). Photoinhibition-induced reduction in photosynthesis is alleviated by abscisic acid, cytokinin and brassinosteroid in detached tomato leaves. Plant Growth Regul. 60, 175-182. doi: 10.1007/s10725-009-9439-Z

Ogweno, J. O., Song, X. S., Shi, K., Hu, W. H., Mao, W. H., Zhou, Y. H., et al. (2008). Brassinosteroids alleviate heat-induced inhibition of photosynthesis by increasing carboxylation efficiency and enhancing antioxidant systems in Lycopersicon esculentum. J. Plant Growth Regul. 27, 49-57. doi: 10.1007/s00344-0079030-7

Özdemir, F., Bor, M., Demiral, T., and Türkan, I. (2004). Effects of 24-epibrassinolide on seed germination, seedling growth, lipid peroxidation, proline content and antioxidative system of rice (Oryza sativa L.) under salinity stress. Plant Growth Regul. 42, 203-211. doi: 10.1023/B:GROW.0000026509.25995.13

Peng, Z., Han, C., Yuan, L., Zhang, K., Huang, H., and Ren, C. (2011). Brassinosteroid enhances jasmonate-induced anthocyanin accumulation in Arabidopsis seedlings. J. Integ. Plant Biol. 53, 632-640. doi: 10.1111/j.17447909.2011.01042.x

Pokotylo, I. V., Kretynin, S. V., Khripach, V. A., Ruelland, E., Blume, Y. B., and Kravets, V. S. (2014). Influence of 24-epibrassinolide on lipid signalling and metabolism in Brassica napus. Plant Growth Regul. 73, 9-17. doi: 10.1007/s10725-013-9863-y

Rady, M. M. (2011). Effect of 24-epibrassinolide on growth, yield, antioxidant system and cadmium content of bean (Phaseolus vulgaris L.) plants under salinity and cadmium stress. Sci. Hortic. 129, 232-237. doi: 10.1016/j.scienta.2011.03.035

Rady, M. M., and Osman, A. S. (2012). Response of growth and antioxidativve system of heavy metal contaminated tomato plants 24-epibrassinolide. Afr. J. Agric. Res. 7, 3249-3254.

Raghu, K., Mahesh, K., Divya Sri, N., and Rao, S. S. R. (2014). Effect of brassinosteroids on the seed germination and seedling growth of radish (Raphanus sativus L) under arsenic toxicity stress. Intl. J. Dev. Res. 9, 1929-1933.

Ramakrishna, B., and Rao, S. S. R. (2013). Preliminary studies on the involvement of glutathione metabolism and redox status against zinc toxicity in radish seedlings by 28-homobrassinolide. Environ. Expt. Bot. 96, 52-58. doi: 10.1016/j.envexpbot.2013.08.003

Rao, S. S. R., Vardhini, B. V., Sujatha, E., and Anuradha, S. (2002). Brassinosteroids - new class of phytohormones. Curr. Sci. 82, 1239-1245.

Saka, H., Fujii, S., Imakawa, A. M., Kato, N., Watanabe, S., Nishizawa, T., et al. (2003). Effect of brassinolide applied at the meiosis and flowering stages on the levels of endogenous plant hormones during grain filling in rice plant (Oryza sativa L.). Plant Prod. Sci. 6, 36-42. doi: 10.1626/pps.6.36

Savaliya, D. D., Mandavia, C. K., and Mandavia, M. K. (2013). Role of brassinolide on enzyme activities in groundnut under water deficit stress. Indian J. Agric. Biochem. 26, 92-96.

Shahbaz, M., and Ashraf, M. (2007). Influence of exogenous application of brassinosteroids on growth and mineral nutrients of wheat (Triticum aestivum L.) under saline conditions. Pak. J. Bot. 39, 513-522.

Shahbaz, M., Ashraf, M., and Athar, H. U. R. (2008). Does exogenous application of 24-epibrassinolide ameliorate salt induced growth inhibition in wheat (Triticum aestivum L.)? Plant Growth Regul. 55, 51-64. doi: 10.1007/s10725-008-9262-y

Shahid, M. A., Pervez, M. A., Balal, R. M., Mattson, N. S., Rashid, A., Ahmad, R., et al. (2011). Brassinosteroid (24-epibrassinolide) enhances growth and alleviates the deleterious effects induced by salt stress in pea (Pisum sativum L.). Aust. J. Crop Sci. 5, 500-510.

Shang, Q., Song, S., Zhang, Z., and Guo, S. (2006). Exogenous brassinosteroid induced salt resistance of cucumber (Cucumis sativus L.) seedlings. Sci. Agric. Sinica 39, 1872-1877.

Sharma, I., Bhardwaj, R., and Pati, P. K. (2013a). Stress modulation response of 24-epibrassinolide against imidacloprid in an elite indica rice variety Pusa Basmati-1. Pesticide Biochem. Physiol. 105, 144-153. doi: 10.1016/j.pestbp.2013. 01.004

Sharma, I., Ching, E., Saini, S., Bhardwaj, R., and Pati, P. K. (2013b). Exogenous application of brassinosteroid offers tolerance to salinity by altering stress responses in rice variety Pusa Basmati-1. Plant Physiol. Biochem. 69, 17-26. doi: 10.1016/j.plaphy.2013.04.013

Sharma, I., Pati, P. K., and Bhardwaj, R. (2010). Regulation of growth and antioxidant enzyme activities by 28 -homobrassinolide in seedlings of Raphanus sativus L. under cadmium stress. Indian J. Biochem. Biophys. 47, 172-177.

Sharma, I., Pati, P. K., and Bhardwaj, R. (2011a). Effect of 24-epibrassinolide on oxidative stress markers induced by nickel-ion in Raphanus sativus L. Acta Physiol. Plant 33, 1723-1735. doi: 10.1007/s11738-010-0709-1

Sharma, I., Pati, P. K., and Bhardwaj, R. (2011b). Effect of 28-homobrassinolide on antioxidant defence system in Raphanus sativus L. under chromium toxicity. Ecotoxicology 20, 862-874. doi: 10.1007/s10646-011-0650-0

Sharma, N., Hundal, G. S., Sharma, I., and Bharadwaj, R. (2012). Effect of 24epibrssinolide on protein content and activities of glutathione-S-transferase and poly phenol oxidase in Raphanus sativus L. plants under cadmium and mercury metal stress. Terrest. Aquat. Toxicol. 6, 1-7.

Sharma, P., Bhardwaj, R., Arora, N., Arora, H. K., and Kumar, A. (2008). Effects of 28-homobrassinolide on nickel uptake, protein content and antioxidative defence system in Brassica juncea. Biol. Plant 52, 767-770. doi: 10.1007/s10535008-0149-6

Singh, I., and Shono, M. (2005). Physiological and molecular effects of 24epibrassinolide, a brassinosteroid on thermotolerance of tomato. Plant Growth Regul. 47, 111-119. doi: 10.1007/s10725-005-3252-0

Song, S., Liu, W., Guo, S., Shang, Q., and Zhang, Z. (2006). Salt resistance and its mechanism of cucumber under effects of exogenous chemical activator. Yingyong Shengtai Xuebao 17, 1871-1876.

Strnad, M., and Kohout, L. (2003). A simple brassinolide analogue 2a, 3a-dihydroxy-17b-(3-methyl butynyloxyl) 7-oxa-B-homo-5a androstan-6-one which induces bean second node splitting. Plant Growth Regul. 40, 39-47. doi: 10.1023/A:1023091918892

Suzuki, Y., Saso, K., Fujioka, S., Yoshida, S., Nitasaka, E., Nagata, S., et al. (2003). A dwarf mutant strain of Pharbitis nil, Uzukobito (kobito), has defective brassinosteroids biosynthesis. Plant J. 36, 401-410. doi: 10.1046/j.1365313X.2003.01887.x

Tabur, S., and Demir, K. (2009). Cytogenetic response of 24-epibrassinolide on the root meristem cells of barley seeds under salinity. Plant Growth Regul. 58, 119-123. doi: 10.1007/s10725-008-9357-5

Talaat, N. B., and Shawky, B. T. (2013). 24-Epibrassinolide alleviates saltinduced inhibition of productivity by increasing nutrients and compatible 
solutes accumulation and enhancing antioxidant system in wheat (Triticum aestivum L.). Acta Physiol. Plant. 35, 729-740. doi: 10.1007/s11738-01 2-1113-9

Tao, Y. Z., Zheng, J., Xu, Z. M., Zhang, X. H., Zhang, K., and Wang, G. Y. (2004). Functional analysis of $Z m D W F 1$, a maize homolog of Arabidopsis brassinosteroids biosynthetic DWF1/DIM gene. Plant Sci. 167, 743-751. doi: 10.1016/j.plantsci.2004.05.012

Upreti, K. K., and Murti, G. S. R. (2004). Effects of brassinosteroids on growth, nodulation, phytohormone content and nitrogenase activity in French bean under water stress. Biol. Plant 48, 407-411. doi: 10.1023/B:BIOP.0000041094.13342.1b

Vardhini, B. V. (2011). Studies on the effect of brassinolide on the antioxidative system of two varieties of sorghum grown in saline soils of Karaikal. Asian Aust. J. Plant Sci. Biotechnol. 5, 31-34.

Vardhini, B. V. (2012a). Application of brassinolide mitigates daline stress of certain metabolites of sorghum grown in Karaikal. J. Phytol. 4, 1-3.

Vardhini, B. V. (2012b). Effect of brassinolide on certain enzymes of sorghum plant grown in saline soils of Karaikal. J. Phytol. 4, 30-33.

Vardhini, B. V. (2013a). Comparative study of Sorghum vulgare Pers. Grown in two experimental sites by brassinolide application at vegetative, flowering and grain filling stage. Proc. Andhra Pradesh Akad. Sci. 15, 75-79.

Vardhini, B. V. (2013b). "Brassinosteroids role for amino acids, peptides and amines modulation in stressed plants - a review," in Plant Adaptation to Environmental Change: Significance of Amino Acids and their Derivatives, eds N. A. Anjum, S. S. Gill, and R. Gill (Wallingford, CT: CAB International), 300-316.

Vardhini, B. V., Anuradha, S., and Rao, S. S. R. (2006). Brassinosteroids - a great potential to improve crop productivity. Indian J. Plant Physiol.11, 1-12.

Vardhini, B. V., and Rao, S. S. R. (1998). Effect of brassinosteroids on growth, metabolite content and yield of Arachis hypogaea. Phytochemistry 48, 927-930. doi: 10.1016/S0031-9422(97)00710-3

Vardhini, B. V., and Rao, S. S. R. (1999). Effect of brassinosteroids on nodulation and nitrogenase activity in groundnut (Arachis hypogaea. L). Plant Growth Regul. 28, 165-167. doi: 10.1023/A:1006227417688

Vardhini, B. V., and Rao, S. S. R. (2002). Acceleration of ripening of tomato pericarp discs by brassinosteroids. Phytochemistry 61, 843-847. doi: 10.1016/S00319422(02)00223-6

Vardhini, B. V., and Rao, S. S. R. (2003a). Amelioration of water stress by brassinosteroids on seed germination and seedling growth of three varieties of sorghum. Plant Growth Regul. 41, 25-31. doi: 10.1023/A:1027303518467

Vardhini, B. V., and Rao, S. S. R. (2003b). Influence of brassinosteroids on growth, yield, metabolite content and enzyme activities of tomato (Lycopersicon esculentum Mill.). Proc. Natl. Acad. Sci. India B Biol. Sci. 73, 307-315.

Vardhini, B. V., and Rao, S. S. R. (2005). Influence of brassinosteroids on seed germination and seedling growth of sorghum under water stress. Indian J. Plant Physiol. 10, 381-385.

Vardhini, B. V., Rao, S. S. R., and Rao, K. V. N. (2008). "Effect of brassinolide on growth, yield, metabolite content and enzyme activities of tomato (Lycopersicon esculentum) Mill," in Recent Advances in Plant Biotechnology and its Applications, eds S. K. Ashwani Kumar and I. K. Sopory (New Delhi: International Publishing House Ltd.), 133-139.

Vogler, F., Schmalzl, C., Englhart, M., Bircheneder, M., and Sprunck, S. (2014). Brassinosteroids promote Arabidopsis pollen germination and growth. Plant Reproduction 27, 153-167. doi: 10.1007/s00497-014-0247-x

Wang, B., Zhang, J., Xia, X., and Zhang, W. H. (2011). Ameliorative effect of brassinosteroid and ethylene on germination of cucumber seeds in the presence of sodium chloride. Plant Growth Regul. 65, 407-413. doi: 10.1007/s10725-0119595-9

Wang, H. H., Feng, T., Peng, X. X., Yan, M. L., Zhou, P. L., and Tang, X. K. (2009). Ameliorative effects of brassinosteroid on excess manganese-induced oxidative stress in Zea mays L. leaves. Agric. Sci. China 8, 1063-1074. doi: 10.1016/S16712927(08)60314-4

Wang, M., Jiang, W. J., and Yu, H. J. (2010). Effects of exogenous epibrassinolide on photosynthetic characteristics in tomato (Lycopersicon esculentum Mill) seedlings under weak light stress. J. Agric. Food Chem. 58, 3642-3645. doi: 10.1021/jf9033893

Wang, Q., Ding, T., Gao, L., Pang, J., and Yang, N. (2012). Effect of brassinolide on chilling injury of green bell pepper in storage. Sci. Hortic. 144, 195-200. doi: 10.1016/j.scienta.2012.07.018
Wang, X. H., Shu, C., Li, H. Y., Hu, X. Q., and Wang, Y. X. (2014). Effects of $0.01 \%$ brassinolide solution application on yield of rice and its resistance to autumn low-temperature damage. Acta Agriculturae Jiangxi 26, 36-38.

Weng, Q., Zhou, B. L., Yu, Y., and Fu, Y. W. (2007). Effects of exogenous ABA, BR, and ETH on changes of lycopene contents in fruit of tomato. Shenyang Nongye Daxue Xuebao 38, 784-787.

Xi, Z., Wang, Z., Fang, Y., Hu, Z., Hu, Y., Deng, M., et al. (2013). Effects of 24epibrassinolide on antioxidation defense and osmoregulation systems of young grapevines (V. vinifera L.) under chilling stress. Plant Growth Regul. 71, 57-65. doi: 10.1007/s10725-013-9809-4

Xia, X. H., Huang, Y. Y., Wang, L., Huang, L. F., Yu, Y. L., Zhou, Y. H., et al. (2006). Pesticides-induced depression of photosynthesis was alleviated by 24 epibrassinolide pretreatment in Cucumis sativus L. Pesticide Biochem. Physiol. 86, 42-48. doi: 10.1016/j.pestbp.2006.01.005

Xia, X. J., Gao, C. J., Song, L. X., Zhou, Y. H., Shi, K., and Yu, J. Q. (2014). Role of $\mathrm{H}_{2} \mathrm{O}_{2}$ dynamics in brassinosteroid-induced stomatal closure and opening in Solanum lycopersicum. Plant Cell Environ. 37, 2036-2050. doi: 10.1111/pce. 12275

Xia, X. J., Wang, Y. J., Zhau, Y. H., Tao, Y., Mao, W. H., Shi, K., et al. (2009a). Reactive oxygen species are involved in brassinosteroid-induced stress tolerance in cucumber. Plant Physiol. 150, 801-814. doi: 10.1104/pp.109. 138230

Xia, X. J., Zhang, Y., Wu, J. X., Wang, J. T., Zhou, Y. H., Shi, K., et al. (2009b). Brassinosteroids promote metabolism of pesticides in cucumber. J. Agric. Food Chem. 57, 8406-8413. doi: 10.1021/jf901915a

Xia, X. J., Zhou, Y. H., Ding, J., Shi, K., Asami, T., Chen, Z., et al. (2011). Induction of systemic stress tolerance by brassinosteroid in Cucumis sativus. New Phytol. 191, 706-720. doi: 10.1111/j.1469-8137.2011.03745.x

Yamamoto, R., Fujioka, S., Demura, T., Takatsuto, S., Yoshida, S., and Fukuda, H. (2001). Brassinosteroid levels increase drastically prior to morphogenesis of tracheary elements. Plant Physiol. 125, 556-563. doi: 10.1104/pp.125. 2.556

Yuan, G. F., Jia, C. G., Li, Z., Sun, B., Zhang, L. P., Liu, N., et al. (2010). Effect of brassinosteroids on drought resistance and abscisic acid concentration in tomato under water stress. Sci. Hortic. 126, 103-108. doi: 10.1016/j.scienta.2010.06.014

Yuan, L., Shu, S., Sun, J., Guo, S., and Tezuka, T. (2012). Effects of 24epibrassinolide on the photosynthetic characteristics, antioxidant system, and chloroplast ultrastructure in Cucumis sativus L. under $\mathrm{Ca}\left(\mathrm{NO}_{3}\right)_{2}$ stress. Photosynthesis Res. 112, 205-214. doi: 10.1007/s11120-0129774-1

Yusuf, M., Fariduddin, Q., and Ahmad, A. (2011a). 28-Homobrassinolide mitigates boron induced toxicity through enhanced antioxidant system in Vigna radiata plants. Chemosphere 85, 1574-1584. doi: 10.1016/j.chemosphere.2011. 08.004

Yusuf, M., Fariduddin, Q., and Ahmad, A. (2012). 24-Epibrassinolide modulates growth, nodulation, antioxidant system, and osmolyte in tolerant and sensitive varieties of Vigna radiata under different levels of nickel: a shotgun approach. Plant Physiol. Biochem. 57, 143-153. doi: 10.1016/j.plaphy.2012. 05.004

Yusuf, M., Fariduddin, Q., Ahmad, I., and Ahmad, A. (2014). Brassinosteroidmediated evaluation of antioxidant system and nitrogen metabolism in two contrasting cultivars of Vigna radiata under different levels of nickel. Physiol. Mol. Biol. Plant. 20, 449-460. doi: 10.1007/s12298-014-0259-x

Yusuf, M., Fariduddin, Q., Hayat, S., Hasan, S. A., and Ahmad, A. (2011b). Protective response of 28-homobrassinolide in cultivars of Triticum aestivum with different levels of nickel. Arch. Environ. Contam. Toxicol. 60, 68-76. doi: 10.1007/s00244-010-9535-0

Zadvornova, Y. V., Alekseichuk, G. N., Laman, N. A., Khripach, V. A., and Grut, S. (2005). Effect of brassinosteroids on activation of the cell cycle during germination of Brassica oleracea L. seeds. Doklady Natsional'noi Akademii Nauk Belarusi 49, 70-73.

Zhang, M. C., Zhai, Z. X., Tian, X. L., Duan, L. S., and Li, Z. H. (2008). Brassinolide alleviated the adverse effect of water deficits on photosynthesis and the antioxidant of soybean (Glycine max L.). Plant Growth Regul. 56, 257-264. doi: 10.1007/s10725-008-9305-4

Zhang, S., Hu, J., Zhang, Y., Xie, X. J., and Knapp, A. (2007). Seed priming with brassinolide improves lucerne (Medicago sativa $\mathrm{L}$.) seed germination and 
seedling growth in relation to physiological changes under salinity stress. Aust. J. Agric. Res. 58, 811-815. doi: 10.1071/AR06253

Zhang, Y. P., Zhu, X. H., Ding, H. D., Yang, S. J., and Chen, Y. Y. (2013). Foliar application of 24-epibrassinolide alleviates high-temperature-induced inhibition of photosynthesis in seedlings of two melon cultivars. Photosynthetica 51, 341-349. doi: 10.1007/s11099-013-0031-4

Zhao, Y., Liang, Z. Y., and Yang, Y. J. (2013). Effects of exogenous brassinosteroid on Cd tolerance in Solatium nigrum seedlings. Zhongguo Shengtai Nongye Xuebao $21,872-876$.

Zhiponova, M. K., Vanhoutte, I., Boudolf, V., Betti, C., Dhondt, S., Coppens, F., Mylle, E., et al. (2013). Brassinosteroid production and signaling differentially control cell division and expansion in the leaf. New Phytol. 197, 490-502. doi: 10.1111/nph.12036

Zhou, A., Wang, H., Walker, J. C., and Li, J. (2004). BRL1, a leucine-rich repeat receptor-like protein kinase, is functionally redundant with BRI1 in regulating Arabidopsis brassinosteroid signaling. Plant J. 40, 399-409. doi: 10.1111/j.1365313X.2004.02214.X
Conflict of Interest Statement: The authors declare that the research was conducted in the absence of any commercial or financial relationships that could be construed as a potential conflict of interest.

Received: 30 November 2014; accepted: 19 December 2014; published online: 12 January 2015.

Citation: Vardhini BV and Anjum NA (2015) Brassinosteroids make plant life easier under abiotic stresses mainly by modulating major components of antioxidant defense system. Front. Environ. Sci. 2:67. doi: 10.3389/fenvs.2014.00067

This article was submitted to Environmental Toxicology, a section of the journal Frontiers in Environmental Science.

Copyright (๑) 2015 Vardhini and Anjum. This is an open-access article distributed under the terms of the Creative Commons Attribution License (CC BY). The use, distribution or reproduction in other forums is permitted, provided the original author $(s)$ or licensor are credited and that the original publication in this journal is cited, in accordance with accepted academic practice. No use, distribution or reproduction is permitted which does not comply with these terms. 